\title{
Por y para mujeres: motivando su participación en el desarrollo de materiales para la atención en salud reproductiva
}

\author{
Valerie J. Hull \\ Barbara L. Ibrahim \\ Population Council \\ Nadia Farah \\ Blanca Figueroa \\ Margaret Winn
}

Follow this and additional works at: https://knowledgecommons.popcouncil.org/departments_sbsr-pgy

Part of the Family, Life Course, and Society Commons, Gender and Sexuality Commons, International Public Health Commons, Maternal and Child Health Commons, Public Health Education and Promotion Commons, and the Women's Health Commons

How does access to this work benefit you? Let us know!

\section{Recommended Citation}

Hull, Valerie J., Barbara L. Ibrahim, Nadia Farah, Blanca Figueroa, and Margaret Winn. 1992. "Por y para mujeres: motivando su participación en el desarrollo de materiales para la atención en salud reproductiva," Quality/Calidad/Qualité no. 4. New York: Population Council. 


\section{Por y para Mujeres:}

Motivando su Participación en el Desarrollo de Materiales para la Atención en Salud Reproductiva

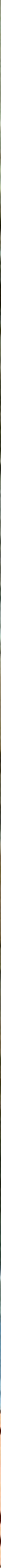


Calidad/Quality/Qualité, una publicación del Population Council, resalta ejemplos de programas de planificación familiar y salud reproductiva que se esmeran por dar servicios de alta calidad. Esta serie es parte del Programa Robert H. Ebert en Temas Críticos en Salud Reproductiva y Población, el cual, mediante esfuerzos científicos y prácticos, busca mejorar y expandir el alcance y la calidad de los servicios en salud reproductiva. Los fundamentos filosóficos del programa y de esta serie, parten de que las mujeres y sus parejas tienen derecho a recibir de los proveedores de servicios de salud reproductiva un trato respetuoso, información, continuidad en la atención y la presentación de opciones para elegir un método anticonceptivo. Los folletos reflejan uno de estos elementos necesarios para mejorar la calidad de los programas de planificación familiar.

Los proyectos para la documentación de la serie Calidad/Quality/Qualité los selecciona un Comité Asesor integrado por personas con una amplia experiencia en el campo de la salud reproductiva y comprometidas con el mejoramiento de la calidad de atención de los servicios. Estos proyectos muestran avances importantes en uno o más de los siguientes aspectos: ampliar la variedad de métodos anticonceptivos y tecnologias disponibles; suministrar la información que los clientes necesitan para tomar decisiones informadas sobre el manejo de su propia salud; reforzar la calidad de la interacción cliente/ proveedor y favorecer el contacto constante entre proveedores y clientes; ensayar estrategias innovadoras para mejorar la capacidad gerencial de los directivos y las habilidades técnicas de los proveedores de servicios de diferentes niveles de atención; expandir la gama de servicios y la información suministrada más allá de lo que usualmente se llama "planificación familiar"; y proporcionar atención en salud reproductiva a grupos desfavorecidos y sin acceso a los servicios.

Ninguno de los proyectos documentados en estas series se ofrece como un modelo para replicar. Por el contrario, cada uno está presentado como un ejemplo creativo inusual de valores, objetivos e implementación. Las "experiencias de aprendizaje" demuestran la actitud de autocrítica que se requiere para anticipar las necesidades de servicios de los clientes y encontrar los medios para satisfacerlas con los recursos existentes. Esta postura reflexiva se ejemplifica mediante la voluntad de responder tanto a cambios de las necesidades de los clientes como de transformaciones sociales y económicas más amplias que afectan a las sociedades. Creemos que documentar las decisiones cruciales que estos programas han tomado ayudará a reforzar la creencia de que la satisfacción personal con los servicios de salud reproductiva, está intimamente ligada con el cumplimento de metas sociales más amplias en salud y población.

La publicación de la edición original en inglés de Calidad/Quality/Qualité fue posible gracias al apoyo de la Fundación Ford, la Fundación John D. y Catherine T. MacArthur y el Fondo de las Naciones Unidas para Actividades de Población (FNUAP).

La edición en español fue financiada por el proyecto INOPAL III (Investigación Operativa y Asistencia Técnica en Planificación Familiar y Salud Reproductiva en América Latina y el Caribe) que a su vez es financiado por la Agencia Internacional para el Desarrollo de los Estados Unidos (USAID) mediante el contrato No. CCP-95-C-00-00007-00.

Traducción al español:

Responsable de la publicación:
Adelaida Gómez del Campo

Silvia Llaguno

Número Cuatro 1992 ISSN 0-8734-057-2 Copyright $C$ The Population Council 1992

Edición en Español ISBN 968-5092-01-X 


\title{
Por y para Mujeres: \\ Motivando su Participación en el \\ Desarrollo de Materiales para la \\ Atención en Salud Reproductiva
}

\author{
Introducción y Discusión por Valerie Hull \\ Estudios de Caso por: Barbara Ibrahim y Nadia Farah: Egipto \\ Blanca Figueroa: Perú, Margaret Winn: Pacífico Sur
}

\section{Introducción}

\section{Conocimiento es Poder}

La información es la clave mediante la cual nos comprendemos y nos adaptamos al cambio. También es la base sobre la cual ampliamos el conocimiento sobre nosotros mismos y ejercemos un mayor control sobre nuestras vidas. En el área de la salud, el acceso a la información permite conocer cuáles servicios están disponibles y fomenta la capacidad para autocuidarse y tomar medidas preventivas, decidir cuándo es necesaria la ayuda de otros, y construir la confianza que las personas necesitan para buscar y usar los servicios de salud disponibles. Si la información se envía por los medios apropiados, ésta puede ser un agente de cambio muy poderoso. Si el mensaje enviado es débil, los resultados son oportunidades perdidas, recursos desperdiciados y aún la difusión de información dañina.

\section{La Salud de la Mujer: ¿Quién "Tiene" la Información?}

Probablemente, en ningún lugar resulta tan importante el acceso a la información como en el área de la salud de las mujeres, particularmente en el área de la salud reproductiva de la mujer. En la segunda mitad de este siglo, la atención de la salud reproductiva ha sido enajenada por los médicos y otros profesionales de la salud, y se ha alejado de los proveedores tradicionales de estos servicios, como las parteras y las mismas mujeres. El conocimiento se ha concentrado en una élite especializada, conformada en su mayoría por hombres, quienes toman muchas decisiones que afectan directamente la salud y el bienestar de las mujeres sin consultarlas. Estas decisiones incluyen definir prioridades para el desarrollo de nuevos anticonceptivos, determinar la distribución del financiamiento disponible entre diferentes tipos de servicios de salud o incluso establecer estándares aceptados para la atención del parto y la alimentación de los recién nacidos.

Sin embargo, las mujeres no dejan de tener sus propios sistemas de información; a menudo comparten entre sí conocimientos de salud, creencias y temores, tanto con mujeres de su misma edad como de otras generaciones. Estos sistemas tradicionales de información pueden ser elementos importantes en la entrega de servicios de alta calidad de atención a la salud, totalmente coherentes con los objetivos de los enfoques de atención primaria y de autocuidado. Infortunadamente, la tendencia de los especialistas de restringir la información al público en general, ha limitado la adquisición de conocimientos precisos sobre nuevas prácticas de salud en estos sistemas tradicionales de información. Irónicamente, los rumores y la información equivocada con frecuencia se filtran en estos sistemas.

\section{Intentos para Enviar el Mensaje}

La mujeres han respondido activamente a esta situación. Desde los inicios del movimiento de planificación familiar, mujeres líderes de muchos países del mundo actuaron enérgica y positivamente para 
ganar el derecho esencial de la mujer de controlar su fecundidad. Además, en los últimos años, los grupos de salud de mujeres, han tenido más voz y participación. Una contribución histórica en esta lucha es el Boston Women's Health Book Collective's Our Bodies, Ourselves. Este libro aporta a las mujeres una fuente de información comprensible en cuestiones de salud. Como resultado del éxito del libro Our Bodies, Ourselves, se han formado en muchos países en vías de desarrollo colectivos de salud de mujeres; uno de los casos presentados en esta publicación describe el trabajo de uno de estos grupos en Egipto.

Gracias a los esfuerzos de mujeres que han trabajado en los niveles institucionales, académicos y operativos, los prestadores de servicios de planificación familiar reconocen hoy en día que es necesario algo más que motivar a los clientes potenciales, que es necesario proporcionar información completa y exacta sobre los métodos anticonceptivos y que, además, los servicios deben ser fácilmente accesibles para facilitar no sólo la adopción, sino el uso continuo de la anticoncepción. También se está empezando a reconocer que da lo mismo no ofrecer información que dar información ininteligible, poco atractiva o que no refleje la realidad de los servicios disponibles.

\section{Materiales de Información hechos por y para Mujeres: Algunos Desafíos Especiales}

Entonces, ¿dónde entran las mujeres en este proceso? ¿hace diferencia la participación de las mujeres en el diseño, evaluación, producción y distribución de materiales de información para la salud? ¿cómo pueden participar las mujeres y qué ocurre cuando participan?

El desarrollo de información en salud por y para mujeres implica no sólo resolver problemas técnicos comunes, sino desafios más básicos del trabajo en el área de atención en salud reproductiva de las mujeres. Las mujeres, especialmente las mujeres pobres, tienden a estar marginadas tanto fisica como socialmente. En comparación con los hombres, tienen una mayor probabilidad de ser analfabetas o de haber perdido la capacidad de leer por falta de práctica, $\mathrm{y}$ de tener más dificultad para interpretar ilustraciones gráficas o aún fotografias. A menudo, también las intimida la información moderna o se les previene de acceder a ella y se les excluye de los procesos de toma de decisiones.

Una dificultad más es que el campo de la salud reproductiva está inmersa en temas a los que se les asignan fuertes cargas morales, usualmente vistos como muy sensibles -ocasionalmente por ellas mismas, pero generalmente por la élite masculina. Esto es sólo un reflejo de las dificultades inherentes que existen en la comunicación entre hombres y mujeres, especialmente en temas como sexualidad, parto y violencia doméstica. Quizás en el futuro los hombres y las mujeres puedan discutir estos temas abiertamente, pero éste no es el caso hoy en día. El proceso de desarrollo de materiales de salud por y para mujeres, permite crear un ambiente seguro en el cual las mujeres pueden hacer preguntas, discutir temas y compartir información de un modo que jamás sería posible en un contexto mixto. El proceso también ayuda a fortalecer la autoestima de las mujeres, a medida que se dan cuenta de que no están solas, que otras mujeres comparten sus problemas y que pueden aprender de las experiencias de unas y otras.

\section{Estudios de Caso}

Los estudios en este número de Calidad/Quality/Qualité describen tres experiencias en diferentes escenarios del mundo en desarrollo. En El Cairo, un colectivo de salud de mujeres elaboró un libro comprehensivo de consulta para mujeres; en Perú, un grupo de mujeres, con una gran participación de su audiencia analfabeta, desarrolló una serie de materiales ilustrados para la enseñanza; y en el Pacífico del Sur, un grupo de producción integrado por mujeres, produjo tres videos motivacionales y para la enseñanza, desarrollados como respuesta a las necesidades expresadas por las mujeres. A pesar del contraste en las características de las audiencias a las que se dirigieron, del proceso de desarrollo y del medio utilizado para enviar los mensajes de salud, todos los proyectos se caracterizaron por la participación activa de las mujeres en todos los niveles y en todas las etapas del desarrollo del proyecto. Las autoras cuentan la historia de su proyecto, comentan la diferencia que hizo la participación de las mujeres, y reflexionan sobre las implicaciones para las actividades futuras. En cada caso, la participación de las mujeres se ha convertido en un legado que comprende más que sólo un conjunto de materiales de información efectivos y bien usados -ha impulsado la movilización de las mujeres que participaron y las ha capacitado para ayudarse a si mismas. 


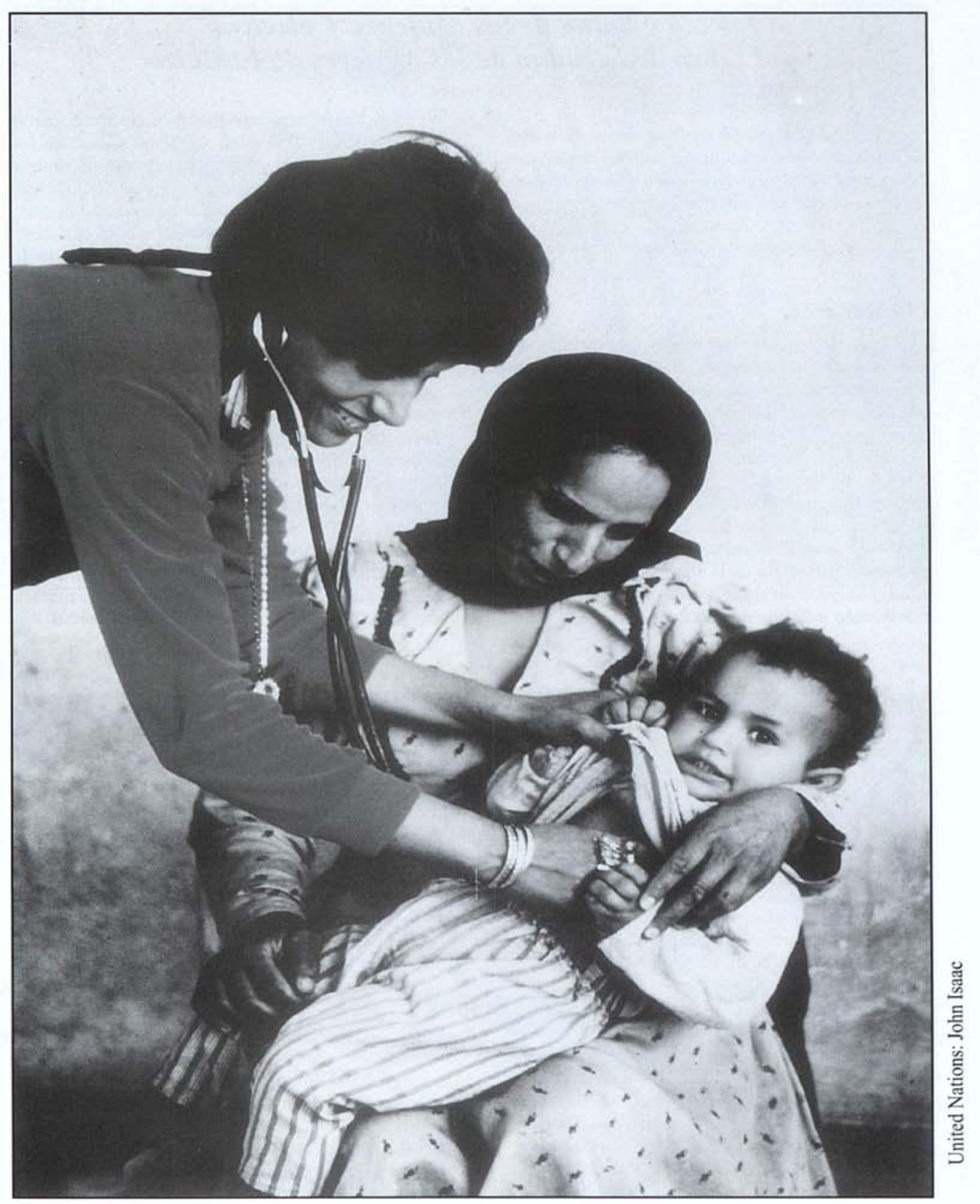




\section{Vida y Salud de las Mujeres: Colectivo del Libro de la Salud de las Mujeres de El Cairo}

Por primera vez en mi vida, lei un libro que me habla directamente, que discute mis problemas reales y no problemas imaginarios que los hombres escritores piensan que sufrimos.

Participante de la evaluación inicial

\section{El Escenario}

Históricamente, los egipcios han utilizado una variedad de recursos tradicionales en la comunidad para resolver sus problemas de salud, tales como curanderos, hueseros y parteras empíricas. Cada vez más, desde la introducción de la medicina moderna, la gente ha confiado su salud a los doctores y a un sistema técnico que desconocen en gran medida. Para las mujeres en particular, esto puede ser un problema, porque las altas tasas de analfabetismo y los códigos de pudor les limitan el acceso fácil a la información sobre salud, y la ignorancia las lleva a un sentimiento de indefensión más que a la buena salud.
Además, una corriente de conservadurismo en el mundo árabe en la última década ha polarizado los puntos de vista sobre los derechos económicos y sociales de las mujeres, incluyendo los derechos a ciertos servicios de salud. Por ello, las consideraciones tanto culturales como médicas han complicado los debates sobre lo apropiado de ciertas técnicas modernas para el control de su fecundidad. Aquellas mujeres que eligen planear el número y el espaciamiento de sus hijos se han encontrado en situaciones paradójicas: por un lado, han luchado por tener acceso a métodos anticonceptivos modernos, como las pastillas, y han denunciado cada vez con más vigor prácticas tradicionales peligrosas, como la circuncisión femenina; mientras que por el otro, han tenido serias reservas sobre la adopción acritica de algunas prácticas médicas y medicamentos modernos. Por ejemplo, hasta que las mujeres iniciaron una campaña pública para su regulación, el controvertido medicamento Depo-provera se vendia sin receta médica en todas las farmacias del pais.

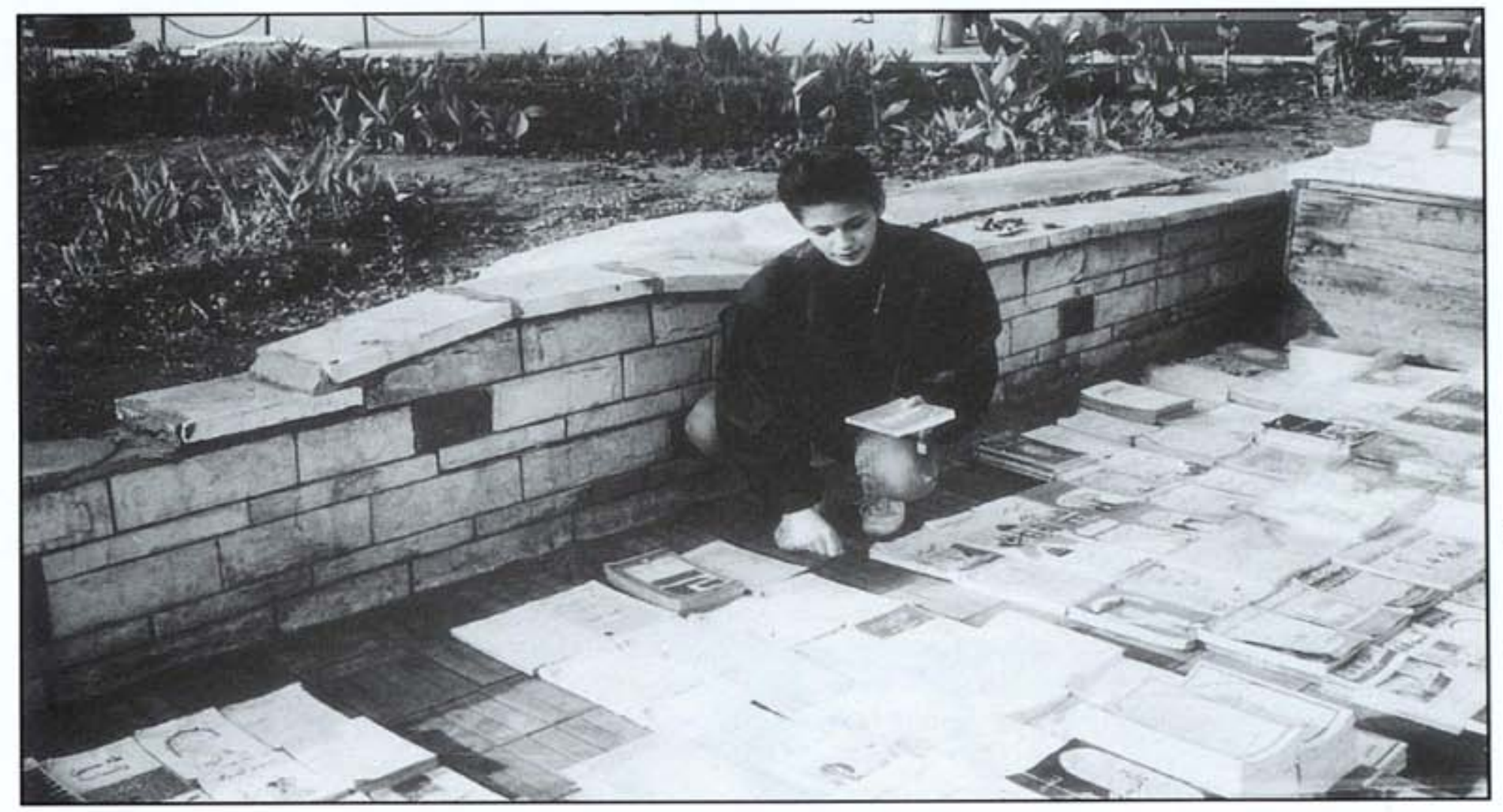




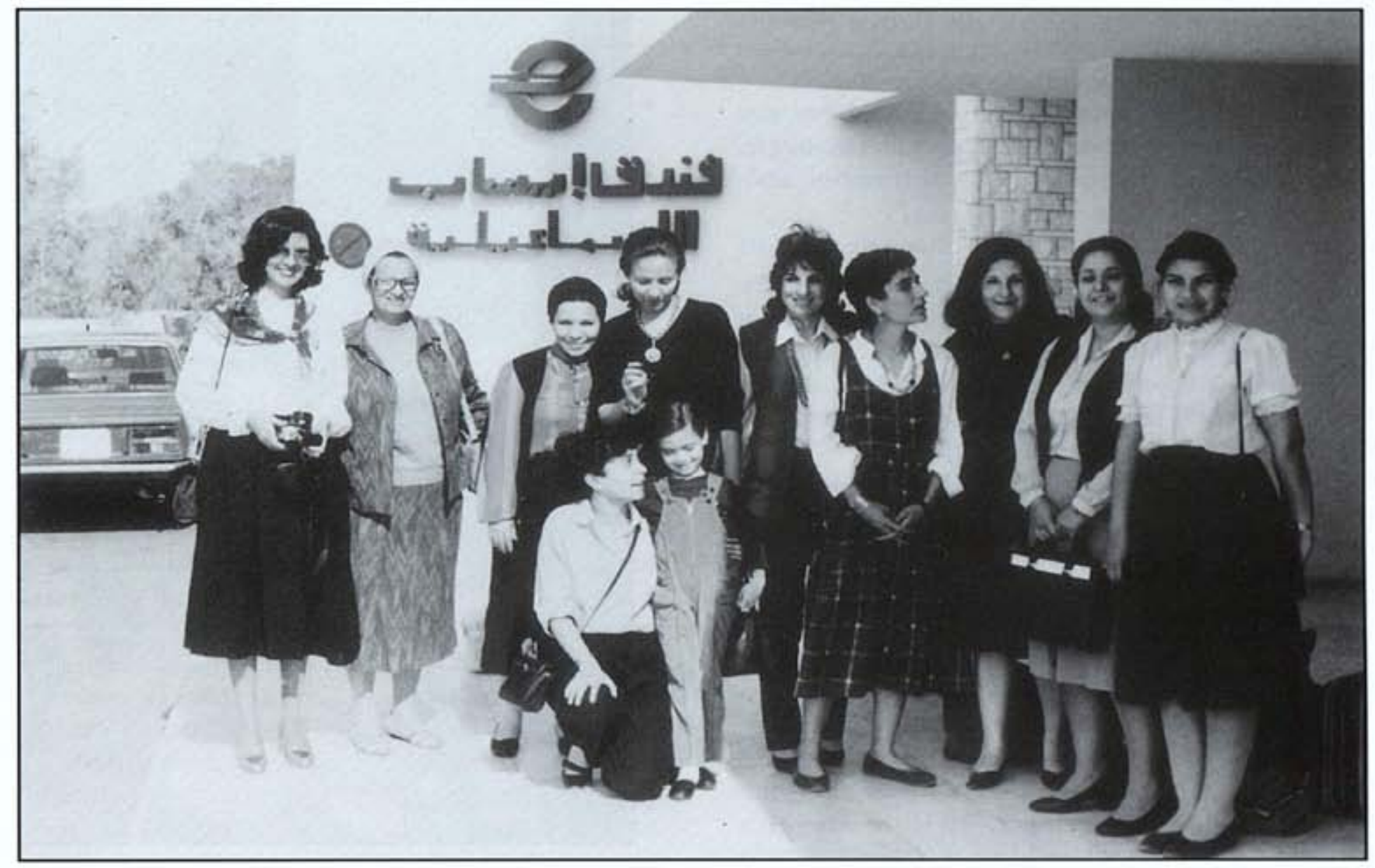

\section{El Colectivo}

La preocupación por estos problemas llevó a un pequeño grupo de mujeres activistas de El Cairo a iniciar discusiones informales relacionadas con la salud reproductiva de las mujeres en Egipto. Algunas de las mujeres estaban familiarizadas con el Boston Women's Health Book Collective y con la guía de salud para las mujeres Our Bodies, Ourselves. Conforme exploraban las diversas opciones para informar a las mujeres egipcias sobre cuestiones de salud, se comprobó que prácticamente no existía una guia o libro con información práctica sobre la salud de las mujeres en árabe. Los libros y revistas disponibles comercialmente eran o muy técnicos o simples al punto de ser incompletos o engañosos. Aún más, la mayoría de las publicaciones contenian un mensaje implícito de que el conocimiento médico es un privilegio que de preferencia debe restringirse a los médicos.

Con base en estas observaciones, el grupo empezó a planear un proyecto de información sobre salud de mujeres, guiados por tres principios básicos: 1) las mujeres tienen el derecho a la información sobre cuestiones que tienen que ver con sus vidas y su salud; 2) la información sobre salud deberá presentarse en forma sencilla, clara y en un lenguaje que las mujeres puedan entender, y 3 ) sobre todo, la información sobre la salud debe tener una orientación práctica, para motivar que las mujeres participen activamente en el cuidado de su propia salud y tomen decisiones informadas.

Antes de decidir exactamente cómo proceder, el grupo solicitó y seleccionó una coordinadora que dedicaría tiempo completo a supervisar el proyecto. La tarea inicial de la coordinadora fue aumentar el tamaño y la extensión del grupo original, formado principalmente por mujeres de la élite de los cientificos sociales. Se invitó a un grupo de 25 mujeres de diferentes clases sociales y edades, y de disciplinas tales como la medicina, la enseñanza, y la comunicación y el desarrollo, para asistir a una reunión para fundar el Colectivo de El Cairo para el Libro sobre la Salud de las Mujeres (Cairo Women's Health Book Colective). La reunión se llevó a cabo en Ismailia, en el Canal de Suez, en abril de 1985. Veintidós de estas mujeres continuaron con el proyecto hasta que concluyó. 


\section{Desarrollo de un Libro de Salud por y para las Mujeres}

Ahora puedo darle a mi hija un libro que responda sus preguntas cientifica y objetivamente. sin hacerla sentir avergonzada de si misma o de su propio cuerpo.

\section{Madre de una joven de 13 años}

Para la primera reunión se programó un retiro de tres días en el cual las mujeres se conocieron y empezaron a definir la naturaleza fundamental del Colectivo, así como las prioridades para la acción. Todas coincidieron en los siguientes puntos básicos para guiar su trabajo futuro:

1) Escribirían una guía de salud para mujeres que reflejara la cultura y las circunstancias actuales de Egipto. Seria un trabajo original, no una traducción o adaptación de un volumen existente. Sin embargo, consultarían ejemplos de otros paises para aprender de sus enfoques.

2) El libro sería escrito desde una perspectiva de mujeres, en un estilo amigable, respetuoso y accesible. Aunque la audiencia a la que se dirigiría el libro tendría un nivel de lectura correspondiente a escolaridad secundaria, el libro llegaria invariablemente más allá de esa audiencia, puesto que la mayor parte de las mujeres egipcias que saben leer a menudo conviven con familiares y vecinos analfabetas.

3) El libro de salud sería escrito objetivamente, sin imponer a los lectores ningún punto de vista particular, sino ayudando a las mujeres a obtener sus propias conclusiones.

4) Todas las decisiones sobre formato, contenido, publicación y distribución se tomarían democráticamente. Todo el grupo discutiría cualquier desacuerdo, de tal forma que el manuscrito reflejaría los puntos de vista de todos los miembros del colectivo, más que los puntos de vista individuales de los autores.

La planeación y producción de este volumen requirió de la comunicación y colaboración intensa tanto entre miembros del Colectivo, como también entre el Colectivo y expertos externos y, aún más importante, con representantes de la audiencia a la que estaba dirigido. La meta del Colectivo no fue sólo producir un libro de salud hecho por mujeres, sino también para las mujeres que lo comprarian y lo usarian.

Cada capitulo fue escrito por dos o tres mujeres que estaban interesadas en el tema. La idea original fue que trabajaran en cada capitulo

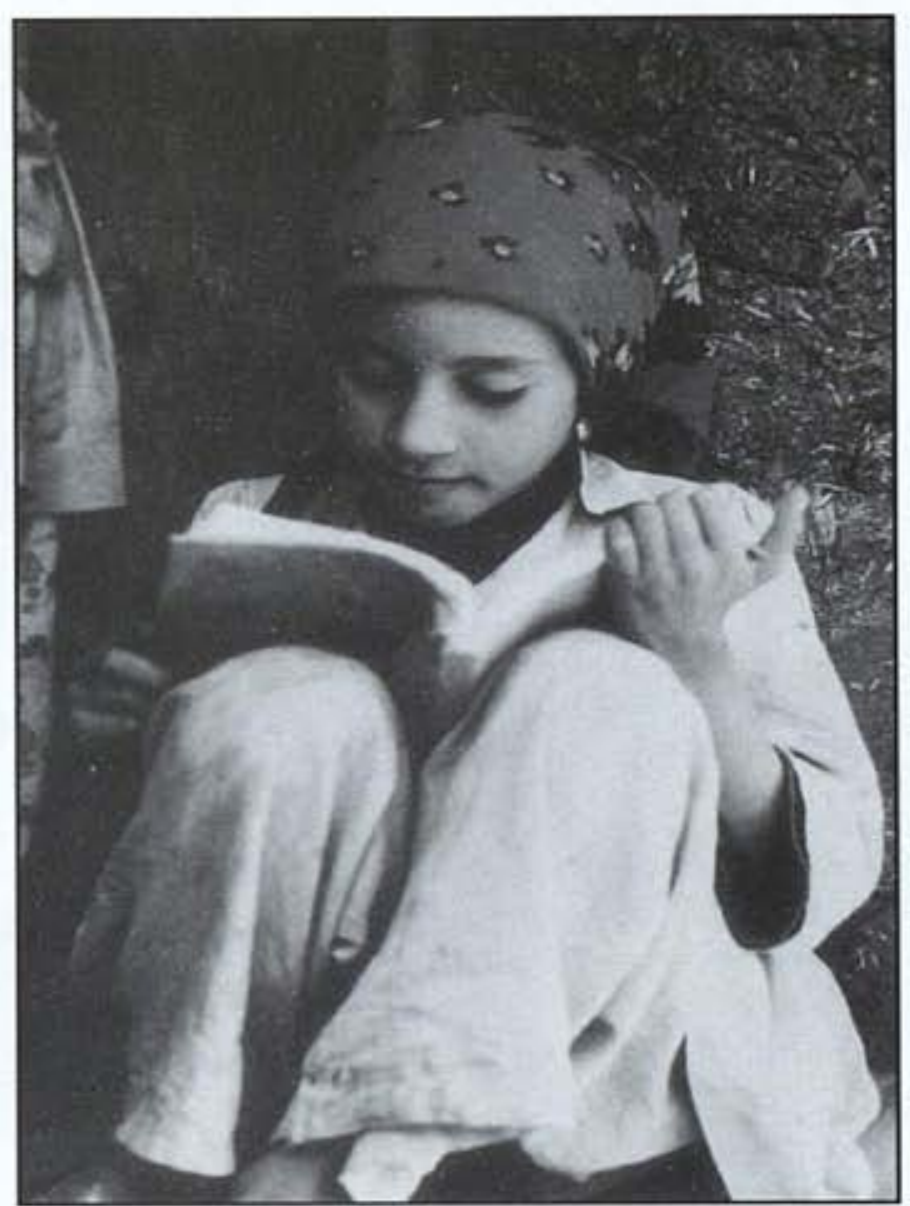

una especialista técnica/médica, una cientifica social y una buena escritora, aunque esto no resultó muy práctico en todos los casos. La coordinadora obtuvo financiamiento de la Fundación Ford y de Oxfam, del Reino Unido, a fin de costear las publicaciones, el salario de la coordinadora y pequeños honorarios para los miembros del equipo de redacción.

Durante dos años, el Colectivo se reunió dos veces por mes para revisar los borradores de los capitulos y garantizar el carácter colaborativo del manuscrito. Los desacuerdos se resolvieron por medio de la negociación y el compromiso. En ocasiones, algunos profesionales médicos sintieron que demasiada información podría ser confusa o peligrosa para las lectoras. Por ejemplo, en el capitulo que trata sobre procedimientos quirúrgicos como la histerectomía, a los médicos les inquietaba que existiera una sección que alentara a las mujeres a cuestionar la necesidad de la cirugía y a buscar una segunda opinión. El Colectivo, sin embargo, decidió a favor del derecho de la mujer a tener información completa, cuestionar los procedimientos médicos y buscar opiniones que corroboraran la recomendación. 


\section{Contenido}

El libro comienza con una serie de capitulos que contemplan las experiencias de las mujeres a lo largo de su ciclo de vida. Para establecer el contexto cultural, el capítulo introductorio discute acerca de las percepciones que tienen las mujeres egipcias sobre si mismas, su estatus y su salud. Los capitulos siguientes tratan las etapas de la niñez, la adolescencia, el matrimonio, la maternidad y la crianza, la menopausia y la vejez. Después, el libro revisa una serie de temas importantes de la salud a lo largo de la edad, incluyendo aquellas que son socialmente determinadas, como la salud ocupacional y la seguridad. Los capítulos se describen en el cuadro de abajo.

Los debates sobre qué temas incluir en el libro y cómo debían manejarse fueron numerosos, situación apenas sorprendente dada la diversidad entre los miembros del Colectivo. El tema de la violencia contra la mujer, por ejemplo, despertó fuertes emociones. Algunos miembros del Colectivo sostuvieron la creencia de que la violación es esencialmente un acto sexual al que la mujer invita por su vestimenta o comportamiento inadecuado. Otros objetaron el capitulo, porque según ellos las cuestiones de violación y abuso marital pondría a todos los hombres bajo una luz negativa y antagonizaría a las lectoras. Se invirtieron muchas horas en discusiones y en un proceso de autoeducación colectiva antes de que estas cuestiones se resolvieran.

Al final, el Colectivo accedió a dedicar un capitulo completo a la violencia contra la mujer. Debido a la naturaleza sensible del material, se tomaron cuidados extras para documentar la violencia (violación, maltrato a esposas, abuso de niños) a partir de datos e investigaciones egipcias. Para lograr un equilibrio, el capítulo no solamente enfoca la violencia de hombres contra mujeres, sino también trata la violencia entre mujeres, incluyendo el abuso físico a los miembros más débiles de la familia y a la ayuda doméstica. Tanto la violencia masculina como la femenina se describen como un resultado de condiciones sociales represivas, más que de las condiciones innatas de cada sexo.

El mayor reto fue encontrar la forma de abordar los temas, sin ofender sentimientos religiosos de musulmanes o cristianos y sin sacrificar la objetividad o la naturaleza feminista del libro. El Colectivo reconoció la importancia de la religión en la sociedad egipcia y realizó interpretaciones positivas de citas del Corán que enfatizan o apoyan la importancia del cuidado de la salud de la mujer, los derechos de las niñas y la igualdad en el matrimonio. A pesar de la variedad de perspectivas religiosas entre miembros del Colectivo, la mayor parte del tiempo estuvieron de acuerdo en la importancia de reforzar aquellos valores religiosos de su sociedad que son el soporte de las mujeres.

En cada etapa de preparación, desde el bosquejo original hasta las versiones subsiguientes, se discutieron cuestiones controvertidas. En resumen, cada capítulo fue revisado al menos cuatro veces, para tomar en cuenta las sugerencias del Colectivo y responder a la crítica del contenido o estilo.

\section{Repaso y Revisión}

Ahora sé mucho sobre mi misma y mi propio cuerpo. He recomendando el libro a todas mis amigas de la escuela y planeamos leerlo con otras amigas y ... a las mujeres en nuestras familias que no pueden leerlo por si mismas.

Una joven de 14 años

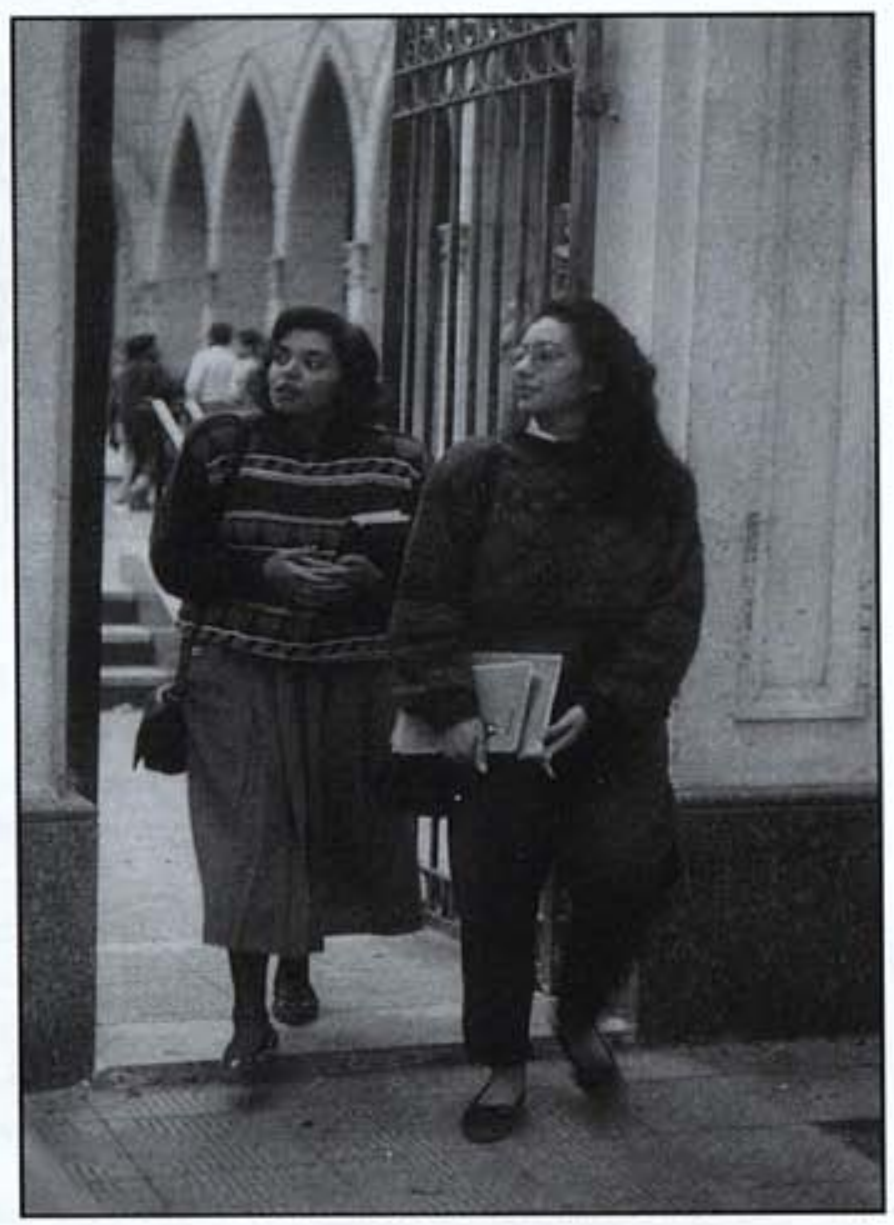




\section{Hayat al Mara... Vida y Salud de las Mujeres en Egipto}

\section{Contenido}

\section{Percepciones de las Mujeres Egipcias Sobre sus Vidas y Salud}

Describe las percepciones que las mujeres tienen sobre sus características biológicas de género, sobre la amistad y el amor, la belleza, el amor y las relaciones sexuales, y los múltiples roles de la mujer en la sociedad. Identifica algunos estereotipos como la percepción de que la femineidad incluye belleza y debilidad.

\section{Infancia: Una Fase Importante en la Vida de las Mujeres}

Discute los cuidados de salud de los niños/as y las formas tradicionales de discriminación entre las niñas (Egipto es uno de los pocos paises donde la tasa de mortalidad infantil femenina es mayor que la masculina) y el daño social y psicológico asociado a la circuncisión femenina.

\section{Adolescencia}

Revisa los cambios fisicos y emocionales de niños y niñas durante la adolescencia. Da información detalladâ sobre la menstruación y la biología reproductiva. Ayuda a las mujeres a lograr un equilibrio entre el deseo de independencia y las necesidades de relación.

\section{Matrimonio y Relaciones Sexuales}

Habla sobre las relaciones sexuales en el contexto del matrimonio (considerando los valores culturales que prevalecen). Enfatiza la importancia de la comunicación y las necesidades de superar los estereotipos tales como el derecho del hombre de iniciar o negar la relación sexual. Hace sugerencias para mejorar la comunicación intima y la satisfacción sexual mutua.

\section{Fertilidad e Infertilidad}

Refuta la noción de que las mujeres son las únicas responsables de la infertilidad (la cual, en niveles socio-económicos bajos, termina frecuentemente en divorcio o abandono). Discute las causas de la infertilidad y métodos que pueden ayudar a las parejas que tienen este problema.

\section{Embarazo, Parto y Lactancia}

Resalta las tradiciones positivas del interés y participación familiar en el embarazo y nacimiento, así como la importancia de la supervisión médica durante el embarazo desde la etapa temprana. Describe signos que requieren pronta atención médica. Refuerza la tradición de la lactancia materna, mostrando las ventajas emocionales y para la salud. Resalta las ventajas de la participación familiar tradicional.

\section{Aborto}

Trata este tema sensible ofreciendo información de anticonceptivos fiables y varias opciones para un embarazo no deseado (aunque es común inducir un aborto, es ilegal en Egipto, excepto cuando la vida de la madre está en peligro).

\section{Regulación de la Fecundidad: Derechos de las Mujeres, Cuándo y Cómo}

Revisa los principales métodos para regular la fecundidad, mencionando las ventajas y desventajas de cada método y dejando la elección al criterio de cada mujer.

\section{Vida Después de la Menopausia}

Se centra en los aspectos positivos de la vida de las mujeres mayores y cómo hacer frente a los cambios físicos, psicológicos y sociales que acompañan a la menopausia.

\section{Nutrición}

Presenta consejos de nutrición general, resaltando la alta prevalencia de anemia entre las mujeres y niñas, y la forma como puede evitarse y tratarse. 


\section{Infecciones, Enfermedades Malignas y Desórdenes Comunes de Salud}

Recomienda revisiones regulares (una práctica poco común) y superar la reticencia a buscar tratamiento para infecciones, protuberancias u otros problemas tan pronto como aparezcan.

\section{Cuidados Tradicionales de la Salud}

Ofrece un punto de vista equilibrado sobre las prácticas tradicionales, revisando la evidencia cientifica sobre su eficacia, y reconociendo las prácticas benéficas y perjudiciales.

\section{Mujeres y Trabajo}

Revisa de una manera equilibrada los riesgos asociados al trabajo, incluyendo los riesgos para la salud del trabajo en el hogar, como un horno inseguro; riesgos en el trabajo agricola, ocasionados por el uso de fertilizantes y pesticidas; riesgos en oficinas y fábricas ocasionados por materiales y maquinaria insegura. Aunque el empleo de las mujeres se presenta como algo positivo, discute el estrés relacionado con el trabajo que muchas mujeres experimentan al intentar cumplir con responsabilidades múltiples.

\section{Violencia Contra la Mujer}

Incluye violación, abuso físico y psicológico por empleados o miembros de la familia, incesto y trato abusivo a sirvientes y a trabajadores menores de edad. Enfatiza cómo las mujeres pueden protegerse de la violencia.

\section{Presiones Sociales y Psicológicas}

Trata estereotipos de género y sugiere cómo las mujeres pueden aprender a reducir el estrés buscando relaciones más equitativas en la familia, compartiendo sus problemas con los esposos, miembros de la familia o amigos de confianza, o buscando ayuda profesional.

\section{Servicios Disponibles de Salud y Atención Médica en Egipto}

Directorio completo de servicios con énfasis especial en las necesidades de salud de las mujeres.
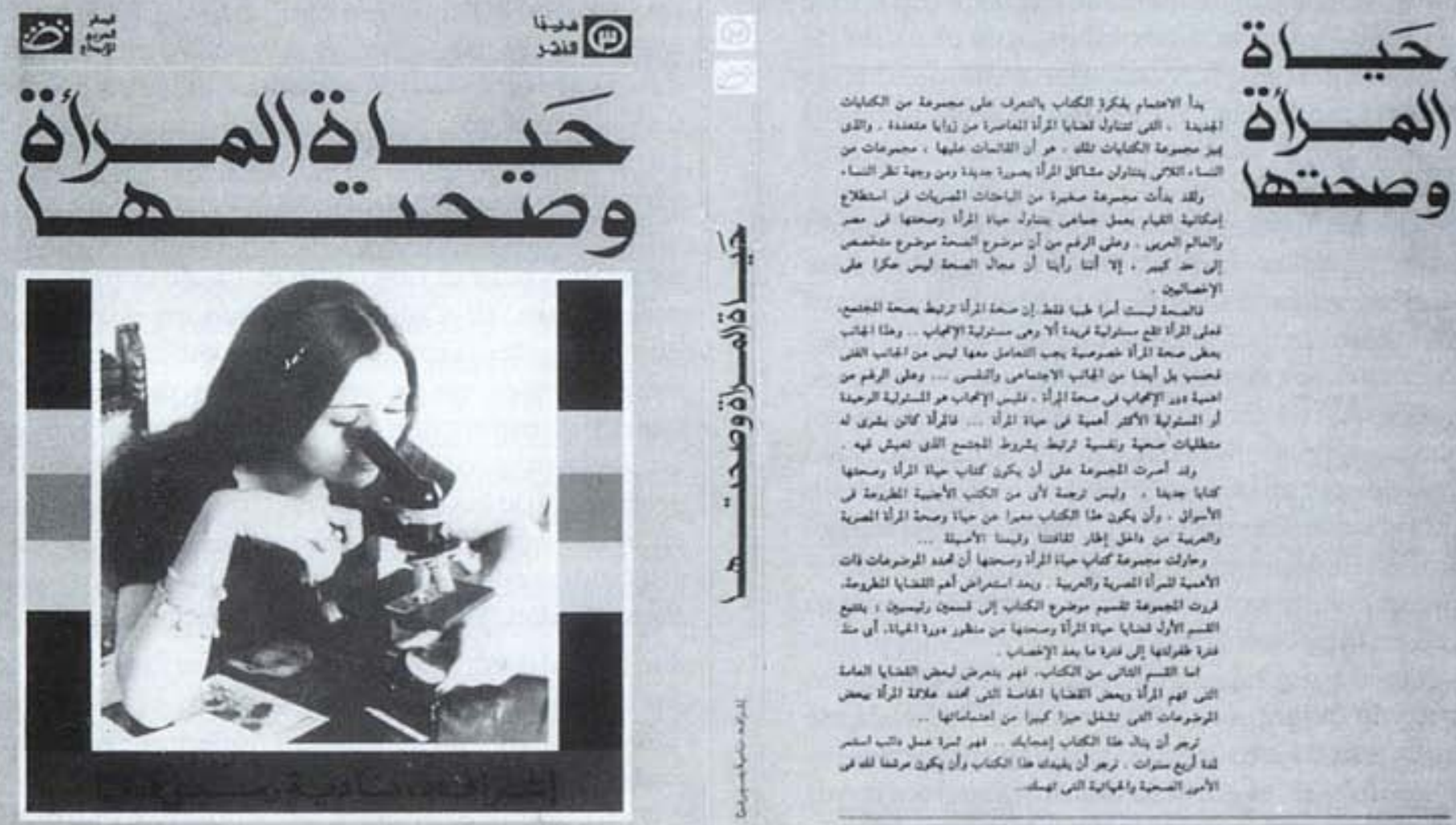
A la mitad, el Colectivo realizó un seminario de dos días para hacer una revisión total de los borradores, para seleccionar gráficas y discutir problemas relacionados con la consistencia y uso del lenguaje árabe. Se invitó a un grupo de revisores, incluyendo a un respetado ginecólogo, un editor profesional y un ilustrador, a participar en este proceso. Uno de los revisores tenia conocimientos de la ley y las tradiciones islámicas. Aunque algunos miembros estuvieron inicialmente en contra de la participación masculina en esta etapa, el Colectivo coincidió en que podría beneficiarse de los puntos de vista y perspectivas masculinas.

Los revisores jugaron un papel importante en el seminario, haciendo numerosas sugerencias que mejoraron la precisión y la claridad del manuscrito. Mostrando algunas actitudes no sexistas -así como un buen número de respuestas estereotipadas- los participantes masculinos dieron una retroalimentación productiva respecto a cómo podría captar el libro el público en general.

Después del seminario, se seleccionaron dos capitulos para pre-probarlos en una muestra de mujeres egipcias. La evaluación buscó medir la reacción del público en aspectos importantes del libro tales como el lenguaje, el estilo, el formato, las ilustraciones y, especialmente, el contenido mismo. ¿Encontrarían aceptable las mujeres la presentación de material sensible sobre sexualidad? ¿Entenderían fácilmente el estilo de la escritura árabe? ¿Encontrarían el tono del libro amistoso y accesible? Cien mujeres con diferentes antecedentes y edades participaron en la preprueba.

Los resultados fueron alentadores: indicaron que el Colectivo habia realizado un libro que cubría las necesidades reales. Muchas mujeres dijeron que era la primera vez que habían leído sobre cuestiones fundamentales de sus vidas desde una perspectiva femenina. La evaluación inicial demostró que el material era accesible, incluso para mujeres con menor educación de lo previsto originalmente. Esto también reforzó la validez del estilo del libro, el cual fue una mezcla de árabe estándar y lenguaje coloquial, como el que se utiliza en los periódicos.

Las ilustraciones que el Colectivo seleccionó iban desde diagramas médicos hasta fotos, desde bosquejos hasta caricaturas. Los lectores de la preprueba inicial favorecieron las ilustraciones cientificas y aprobaron las fotos, pero respondieron negativamente a las caricaturas y tiras cómicas. Este descubrimiento sorprendió a algunos miembros del Colectivo, quienes pensaron que las caricaturas eran una manera atractiva de presentar la información. Al reflexionar, el Colectivo se dio cuenta de que las caricaturas se utilizaban tipicamente en la vida pública egipcia para ridiculizar una idea o a una persona. Sin proponérselo, el uso de las caricaturas disminuía la seriedad de los temas de salud y calificaba negativamente a las mujeres. Como resultado de éstas revisiones, las caricaturas se excluyeron del libro.

Después de la pre-prueba, el texto completo fue revisado por cinco lectoras que habian hecho comentarios excepcionalmente útiles en la preprueba inicial. Las revisiones posteriores garantizaron la consistencia de la sintaxis y de un tono unificado a lo largo del manuscrito, cosa importante en un libro escrito por autores diferentes. Se llevó a cabo una última revisión para eliminar cualquier lenguaje que sonara "como un sermón" a las mujeres.

\section{Publicación y Diseminación}

El producto final, publicado a principios de 1991 por una editorial propiedad de mujeres, tiene una tipografía clara, ilustraciones, un encuadernado durable y un tamaño, entre libro y revista, que garantiza su fácil manejo. En lugar de los derechos de autor, el Colectivo negoció un descuento en todos los pedidos realizados a través de sus miembros, posibilitando asi su distribución entre asociaciones de mujeres y otras organizaciones sociales a un costo mínimo. Aún así, el editor eliminó la mayoria de las ilustraciones planeadas para el libro, con el fin de conservar el precio bajo. El Colectivo estuvo en desacuerdo con esta decisión e insistió en reponer las ilustraciones en la reimpresión del libro. El Colectivo espera que el libro circule ampliamente en Egipto y otros países árabes donde los problemas de las mujeres son similares. Las ventas en países que tienen altos ingresos pueden ayudar a subsidiar ediciones para países de bajos ingresos como Sudán, Yemén, Túnez y Marruecos. 


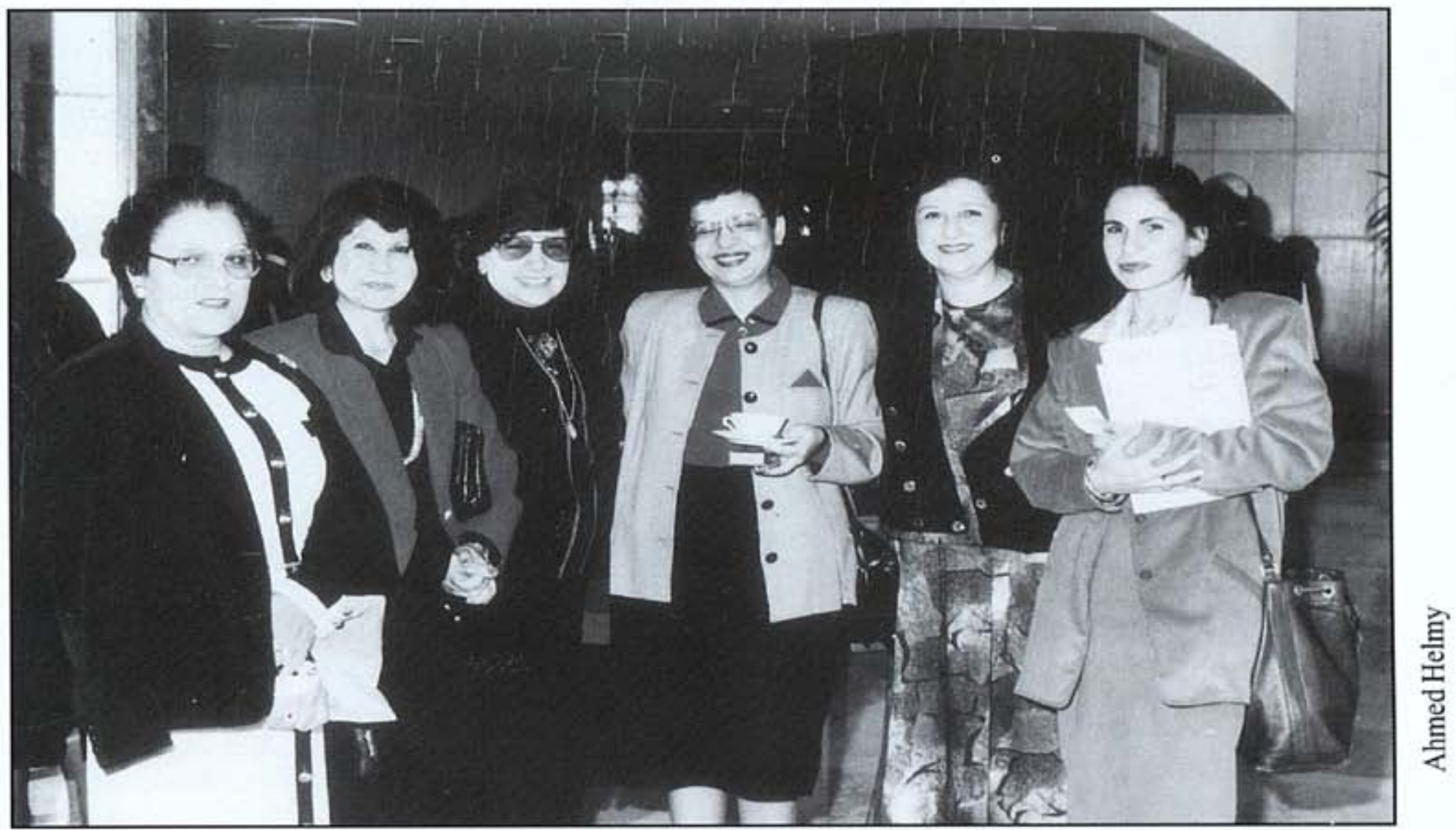

\section{El Futuro}

Por primera vez estoy sintiendo la profunda privación que vivo como mujer analfabeta. Voy a asistir a clases de alfabetización para poder leer el libro yo misma.

\section{Mujer analfabeta de 25 años}

El Colectivo se reunió poco antes de la publicación del libro para planear una conferencia pública, a la que asistirian representantes de medios, líderes de organizaciones no gubernamentales y otros interesados en la salud de las mujeres. La reunión para introducir el libro y a sus autores se llevó a cabo en marzo de 1991. Se alentó a los participantes a diseminar la información del libro tanto como fuera posible y a utilizarlo en sus actividades actuales. Antes de la reunión, se distribuyeron 200 copias gratis a personas importantes y a asociaciones que trabajaban en el campo de la salud de la mujer. Posteriormente, la prensa de El Cairo comentó el libro numerosas veces. La venta del libro ha sido mayor de lo que se anticipó, programándose una segunda impresión para principios de 1992.

Una vez cumplido el propósito de producir la guía de salud, los miembros del Colectivo volvieron su atención al futuro. Algunas de las actividades sugeridas incluyen: el uso del libro en cursos de salud; revisión y separación de capitulos para publicarlos como panfletos; y distribuir el libro fuera de los canales comerciales, como en clínicas, organizaciones de mujeres o escuelas. También mostraron interés en la capacitación de trabajadores sociales en áreas rurales, donde pensaron utilizar el libro como instrumento para los cursos de alfabetización, ya que el porcentaje de analfabetismo de las mujeres es alto. Los miembros del Colectivo buscan explorar otros canales de comunicación, como video, televisión, periódicos y revistas para mujeres, para ampliar los recursos educativos disponibles sobre cuestiones de salud de las mujeres.

Aunque el grupo completo ya no se reúna regularmente, se han formado muchos vínculos duraderos, social y profesionalmente. Todos los miembros opinan que la experiencia de trabajar en la guia de salud para las mujeres los ha enriquecido y les ha dado valiosas lecciones de colaboración. Estas experiencias serán importantes cuando las mujeres egipcias tomen su lugar en el movimiento actual por la libertad de expresión y la participación en la vida nacional. 


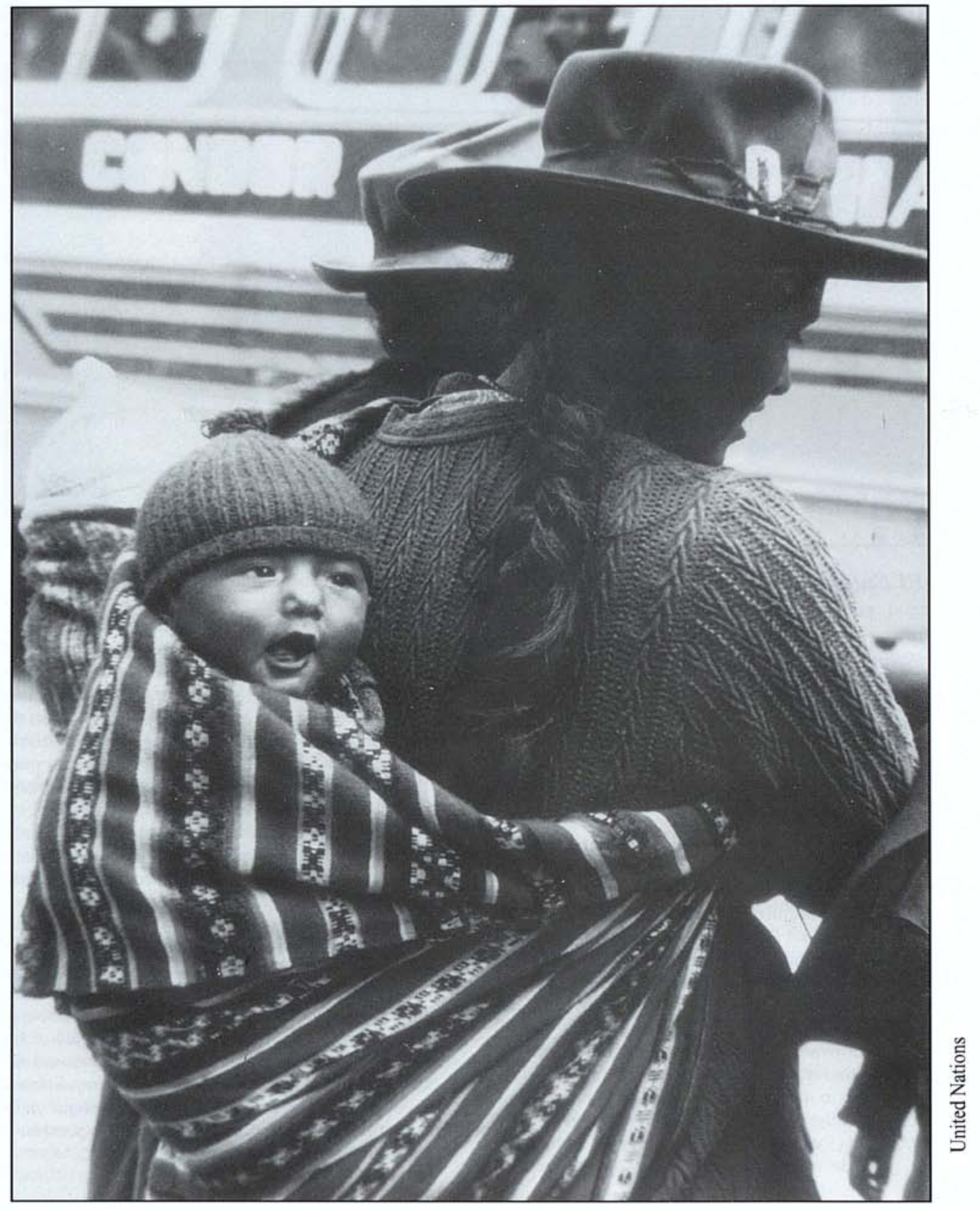




\section{Dando Color a la Vida: Materiales Ilustrados de Salud para Mujeres en Perú}

\section{Antecedentes}

Hasta hace cerca de 12 años, las lideres de organizaciones de mujeres en Perú no estaban interesadas en promover la planificación familiar. Asociaban los mensajes sobre el control de la fecundidad de las mujeres con el "individualismo" retórico de las feministas de países desarrollados. Pero en Perú, como en muchas otras partes del tercer mundo, las lideres del movimiento de mujeres han cambiado su opinión en los últimos años, dándose cuenta que el deseo de controlar el número y el espaciamiento de los hijos es casi universal en las mujeres, sin importar la posición económica o social. Con este reconocimiento, ha aumentado la participación intelectual, política y práctica de las feministas para aumentar el acceso a la información y los servicios relacionados con la sexualidad y la planificación familiar.

\section{Perú-Mujer}

Fue en este contexto, en 1979, en el que dos investigadoras fundaron Perú-Mujer, una organización no gubernamental interesada en ayudar a mejorar la calidad de vida de las mujeres pobres. Usando un método participativo de dinámicas de grupo, Perú-Mujer comenzó dando talleres a grupos de mujeres en todo el Perú sobre temas tales como proyectos de vida, sexualidad y planificación familiar, derechos legales y pequeñas empresas. En los talleres se hizo especial énfasis en que las mujeres definieran y buscaran soluciones a problemas sociales por sí mismas. La ventaja de esta metodología fue la respuesta emocional intensa y la identificación con el grupo que experimentaban las mujeres; mientras que la desventaja, que el personal de Perú-Mujer identificó rápidamente, fue que cuando éstas mujeres regresaran a la vida diaria, tendrian pocas herramientas a su disposición, tanto para mantener su entusiasmo, como para comenzar a cambiar sus propias vidas.

\section{El Proyecto}

Justo en el momento en que el personal de Perú-Mujer estaba luchando con el problema de cómo fomentar el proceso participativo, conocieron los proyectos de PATH (The Programm for Appropiate Technology in Health) en ese tiempo conocido como PIACT (Program for the Introduction and Adaptation of Contraceptive Technology), mismo que utilizaron para desarrollar un folleto sobre planificación familiar y otro sobre un tema de salud de su elección, dirigido a mujeres analfabetas de Perú. PATH/ PIACT inició su trabajo en México a finales de 1970, donde desarrolló una metodología pionera para producir materiales impresos sencillos y fáciles de entender por analfabetas y semianalfabetas. Su enfoque centrado en el cliente, ya usado en América Latina, África y Asia, comprende la capacitación del personal local en el proceso de desarrollo de los materiales.

El personal de Perú-Mujer revisó los materiales desarrollados por los proyectos de PATH/PIACT en otros países y se impresionaron por la actitud respetuosa mostrada hacia los valores culturales. Ellas vislumbraron la oportunidad de incluir a las mujeres tanto en el diálogo como en el proceso de desarrollo de los materiales.

Aunque en Perú existía material visual para la educación en salud primaria, éste no habia sido evaluado para determinar qué tan bien se entendia o aceptaba, especialmente por analfabetas. Además, muchos de estos materiales reflejaban condiciones urbanas que se encontraban en la región costera del país. Puesto que Perú es un país muy variado, una de las primeras cosas que decidió Perú-Mujer, fue que no realizarian un folleto único a escala nacional sobre planificación familiar y vacunación (temas de salud que decidieron promover), sino una versión diferente para cada una de las tres regiones importantes del país: costa, selva y montaña.

\section{Aprendiendo la Metodología}

Las personas analfabetas tienen su propia visión del mundo, una interpretación diferente basada en sus propias experiencias y en un legado de tradición oral. Una persona con habilidades de lectura pobres o inexistentes no ve las ilustraciones de la misma forma que lo hace una persona que 
sabe leer. El proyecto comenzó con un taller de PATH/PIACT para el personal de Perú-Mujer sobre el uso de su metodología. Esta metodologia pone especial interés en la audiencia, en este caso las mujeres locales. Ellas son las "expertas" que saben que información necesitan y cómo se debe presentar la información. Por lo tanto, este enfoque centrado en las mujeres utilizó el conocimiento subyacente y la experiencia que ellas poseian, confirmando las prácticas y conocimientos positivos, y construyendo una base de confianza para empezar a cambiar lo negativo.

Una manera importante de lograr esto fue asegurarse que las mujeres se identificaran con las ilustraciones. Los dibujos de personas que resultan familiares, crean una sensación de identificación emocional y ofrecen una apertura a través de la cual pueden introducirse y retenerse nuevos conceptos e información. Al diseñar los materiales, fue necesario tener en mente que el acceso y uso de la tecnología de salud para la mujer depende en gran medida de sus relaciones con las personas que la rodean, incluyendo relaciones de poder en la familia y la comunidad.

Armadas con las nuevas habilidades que aprendieron, el personal de Perú-Mujer se embarcó en un proyecto de tres fases: 1) hablar con las mujeres sobre planificación familiar e inmunización, para informarse de sus conocimientos, actitudes y valores al respecto; 2) con base en la información obtenida, desarrollar distintos materiales que presentaran la información de los temas en forma clara y culturalmente aceptable, y 3) evaluar los materiales con la audiencia para estar seguras que las mujeres entendian los mensajes y se identificaban con las ilustraciones.

\section{Recolectando Información}

Afortunadamente, Perú-Mujer había estado conduciendo talleres a lo largo del país durante varios años y era bien conocida en diferentes regiones, por lo que no resultó dificil juntar grupos de mujeres analfabetas para discusiones en grupos focales (un método de investigación cualitativo donde un pequeño número de personas hablan sobre un tema dado bajo la dirección de un moderador) sobre los temas elegidos. Aunque al principio las mujeres eran muy reservadas, poco a poco comenzaron a expresar lo que realmente pensaban sobre la planificación familiar o la vacunación. Las mujeres estaban contentas de cooperar en este proceso e incluso explicaban pacientemente y con detalle cuando era necesario. A ellas les gustaba la idea de que alguien se interesara en su forma de vida y que además escribiera un "libro" sobre ellas.

\section{Diseñando los Mensajes}

Cuando terminaron las discusiones en los grupos focales se analizaron los resultados obtenidos. Al mismo tiempo, Perú-Mujer revisó la información técnica y médica de cada tema para asegurarse que los materiales la presentaran adecuadamente. El próximo paso fue desarrollar una serie de mensajes básicos para cada tema. En los folletos de planificación familiar se expresaban cuatro ideas básicas: espaciar los nacimientos permite tener una mejor salud y dar una mayor atención individual a cada hijo; existen métodos modernos de anticoncepción que se pueden utilizar para espaciar el nacimiento de los hijos; aunque la planificación de una familia es una cuestión personal, hay otros problemas comunitarios importantes que necesitan ser resueltos; y es importante que las mujeres se organicen y hablen sobre sus problemas como mujeres.

Ahora los mensajes tenian que traducirse a dibujos. No fue fácil encontrar artistas que entendieran la importancia de reflejar el escenario local en sus ilustraciones. Se hicieron muchos intentos antes de encontrar a la persona correcta. Una vez que el artista terminó la primera serie de dibujos, se pre-probaron las ilustraciones. En cada lugar, se pidió a las mujeres que describieran las ideas representadas en cada dibujo. Cuando no entendian el mensaje, se les preguntaba cómo creían que podía representarse mejor la idea. Por ejemplo, en la región de la montaña, las mujeres dijeron que para mostrar que un hombre era pobre se podía vestirlo con pantalones de lana hechos a mano. Las mujeres se mostraron inflexibles respecto a que las bandas tricolores que adornan sus faldas tuvieran una determinada longitud y anchura, y que sus sombreros locales estuvieran acomodados en el ángulo correcto. Las ilustraciones se aceptaron sólo hasta que al menos 80 por ciento de las mujeres analfabetas pudieran interpretar correctamente el mensaje de cada dibujo.

Al juntar los mensajes, se decidió que para que las pinturas sirvieran como "puente" entre el mundo de las mujeres y la presentación de información médica "nueva", sería menos atemorizante si los mensajes se colocaran de 


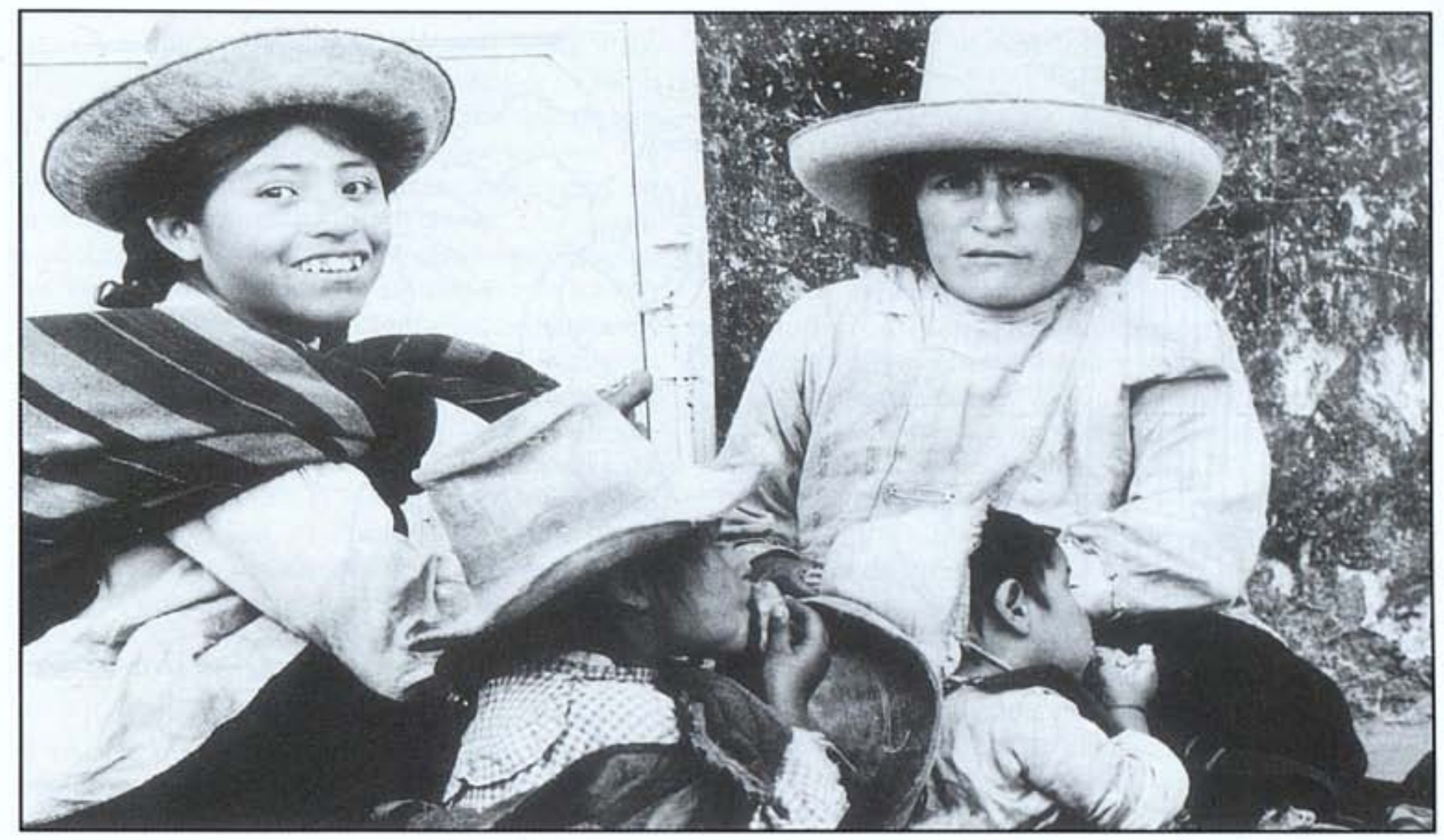

manera tal que contaran una historia común de la vida diaria. Por ejemplo, el folleto de planificación familiar para la costa se llamaba "Los Quispes planean su familia". Quispe es un nombre común entre los emigrantes que viven en áreas marginadas alrededor de Lima y el argumento de la historia es familiar. El marido no tiene trabajo y el niño está enfermo. La madre cuida del niño mientras el marido busca apoyo económico entre sus vecinos, quienes no pueden ayudarlo puesto que ellos están en la misma situación económica. Un vecino recomienda que la madre lleve al niño a un centro salud. Ahí el niño recibe cuidados y el doctor habla con la madre sobre la anticoncepción como una forma de cuidar mejor a los hijos de la pareja. La esposa regresa a su casa, habla con su marido y ambos van a ver al doctor. Eligen un método anticonceptivo del cual hablan luego con sus vecinos. La siguiente imagen muestra una junta de vecinos, donde se discuten problemas comunes. La última ilustración muestra a la mujer en el Club de las Madres hojeando un folleto y hablando sobre planificación familiar.

Durante las discusiones en los grupos focales, las mujeres, particularmente las que provenían de la selva y la montaña, constantemente hablaban sobre el abuso físico por parte de sus maridos. Este fue un tema con una fuerte carga

emocional, especialmente cuando las participantes en el grupo se daban cuenta que no sólo ellas, sino también otras mujeres sufrían el mismo abuso; por esta razón, se incluyó una ilustración de un marido borracho e irresponsable. Por otro lado, en un folleto sobre el parto terminado tiempo después, el marido se presentaba como deseando ayudar a la hora del parto. La meta de no era etiquetar a los hombres, sino asegurarse que las mujeres se identificaran con la ilustración y la compararan con sus propias situaciones, platicando entre ellas mismas si la conducta era apropiada o no, si debía cambiarse y si habia algo que ellas pudieran hacer.

\section{Probando los Folletos}

Una vez que todos los mensajes tuvieron un nivel de comprensión del 80 por ciento o más, se compilaron en forma de folleto y se imprimieron 1,000 copias de cada uno. La comprensión general de los mensajes se evaluó en 10 sitios, en las tres regiones, donde promotores de la salud y trabajadores comunitarios usaron los folletos como auxiliares didácticos en cursos. Todos los promotores de la salud y trabajadores sociales eran nativos o residian en las regiones donde trabajaban y estaban familiarizados con la población local.

Se invitó a diez mujeres analfabetas de cada comunidad a asistir al curso, el cual contaba con 


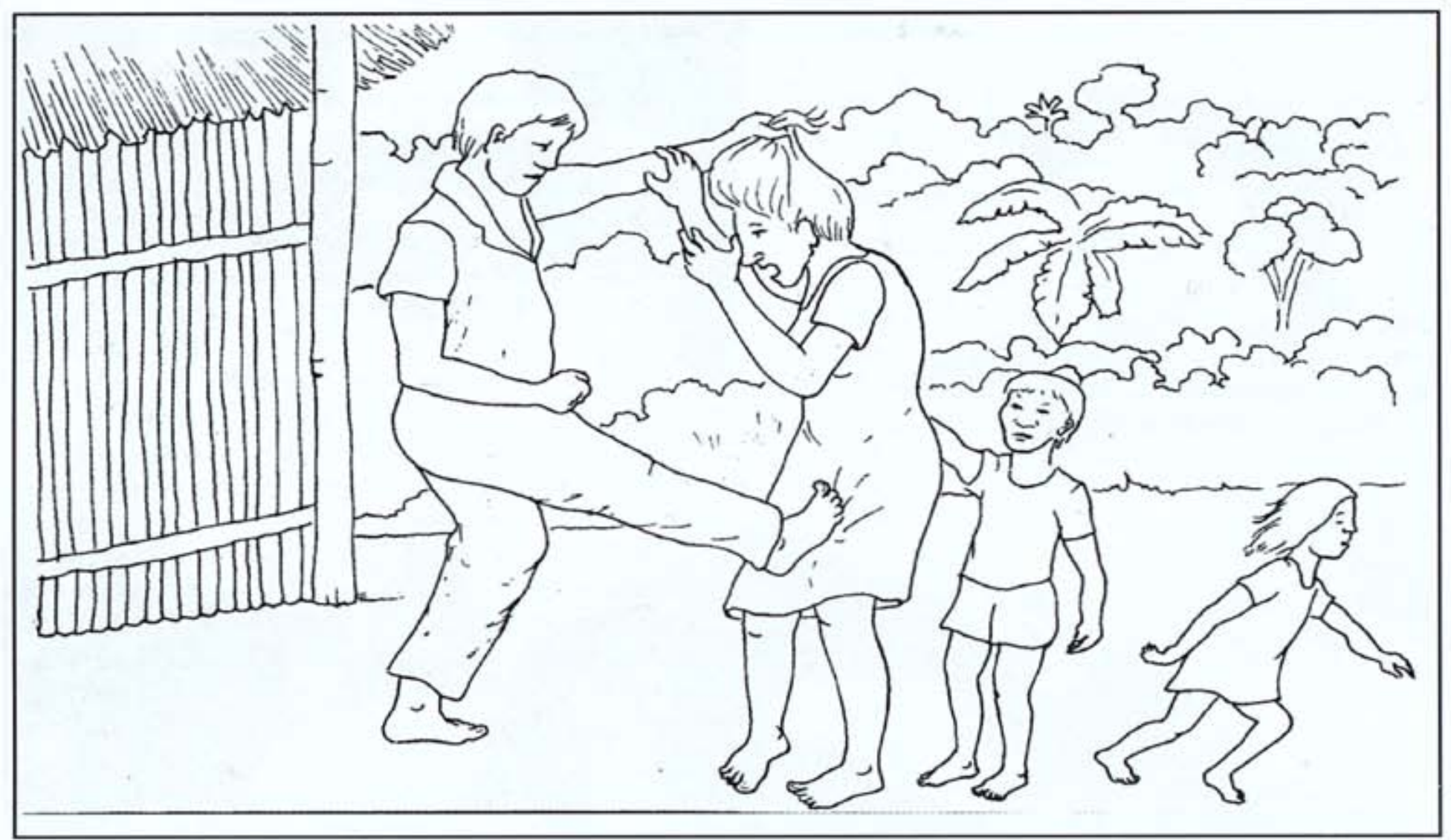

la aprobación de los líderes de la comunidad. A las mujeres se les dio algún apoyo por su participación, teniendo la posibilidad de elegir entre dinero, comida, lana y otros.

Se desarrolló una guía para trabajadores de la salud, que acompañaba a cada folleto. La guía explica, dibujo por dibujo, cómo deben utilizarse los folletos y cómo estimular la discusión. La guía sirvió como centro de las sesiones de capacitación de una semana a la que asistieron los promotores en Lima. Además, en estas sesiones de capacitación, dos pediatras de INPPARES (Instituto Peruano de Paternidad Responsable) especializados en medicina comunitaria, aportaron información adicional sobre planificación familiar y vacunación.

La metodología de la evaluación fue la siguiente: a las mujeres se les enseñaban los dibujos, uno a uno, y se les pedia que explicaran lo que veian. Si no respondian, el promotor las animaba a hablar haciendo preguntas de la guía. Si un dibujo introducía nueva información, se les volvía a preguntar después, para estar seguros de que entendieron claramente el concepto. Al dia siguiente, las mujeres hablaban de lo que habian aprendido el dia anterior. No se cubrian más de cinco a siete ilustraciones por clase.

\section{Coloreando los Folletos}

A cada mujer le dieron lápices de colores y folletos al principio del curso. Al final de cada sesión, el promotor les pedía que colorearan las imágenes que correspondian a lo visto en ese dia. Esta estrategia ya habia sido utilizada antes por Perú-Mujer como parte de sus proyectos legales y se habia encontrado una respuesta favorable.

Muchas mujeres de bajos recursos, particularmente de áreas rurales, nunca antes habian tenido su propio cuaderno y lápices, ¡mucho menos lápices de colores! Cuando las mujeres se llevaban el libro a casa y coloreaban los dibujos, frecuentemente eran ayudadas por sus hijos y en ocasiones por sus maridos. De esta manera, los temas de planificación familiar y vacunación entraban en forma natural al hogar y eran comentados por todos los miembros de la familia. Algunas mujeres solicitaron libros de iluminar extras para compartirlos con sus vecinos $\mathrm{y}$ amigos $\mathrm{y}$, en muchos casos, los vecinos escucharon sobre "los cursos de pintura" y querían asistir. En todos los casos, los cuadernos de iluminar fueron tratados con gran cuidado, se les hicieron fundas especiales o bien se forraban de plástico para que no se ensuciaran. En cada reunión, las mujeres mostraban al grupo el trabajo que había realizado en casa. 
Aunque puede sonar ingenuo pedir a las mujeres que coloreen dibujos, Perú-Mujer ya había aprendido que para las mujeres pobres, que no han hecho otra cosa en sus vidas mas que trabajar, los elementos de entretenimiento en los cursos de capacitación son muy importantes. Darles un cuaderno y varios lápices hizo que éstas mujeres, que no habian asistido a la escuela o que habian aprendido a leer pero lo olvidaron, se sintieran tomadas en cuenta. Además, en la última página del folleto estaba impreso un diploma, en el cual se escribia el nombre de la participante una vez terminado el curso. Las mujeres apreciaban este gesto, ya que añadía una sensación de logro y era valorado por los maridos y las familias. Frecuentemente los diplomas se colgaban en la pared, en ocasiones junto con los folletos.

\section{Evaluación}

Entre dos y cuatro meses después del término de los cursos, los promotores llevaron a cabo sesiones adicionales con los participantes en siete de los diez lugares originales. Se llevaron a cabo discusiones en grupos focales y entrevistas para ver si las mujeres recordaban to que habian aprendido. También se contactó a los centros de salud locales para ver si se había incrementado la demanda de planificación familiar o de vacunación.

En términos de planificación familiar, los participantes se mantuvieron interesados en todos los lugares donde se habian impartido y preguntaron sobre más cursos. Todos pudieron identificar problemas asociados a los nacimientos poco espaciados. En tres lugares, las mujeres pudieron identificar correctamente los anticonceptivos modernos; en otros cuatro lugares no los identificaron todos. El uso de métodos anticonceptivos se habia incrementado de 80 a 100 por ciento en tres lugares, de 50 a 80 por ciento en otros tres y menos del 50 por ciento en uno. En seis sitios, un gran número de mujeres ingresó a cursos de alfabetización después de las sesiones de capacitación. En dos lugares, las instalaciones de planificación familiar reportaron un incremento "considerable" en el uso de sus servicios; cuatro lugares informaron un aumento "ligeramente significativo" y, en uno el incremento fue muy bajo. Se reportaron resultados similares para los servicios de vacunación.

En resumen, los cursos y los cuadernos para colorear, crearon una motivación para utilizar los servicios, no un aumento escandaloso, pero suficiente para probar su utilidad y justificar su

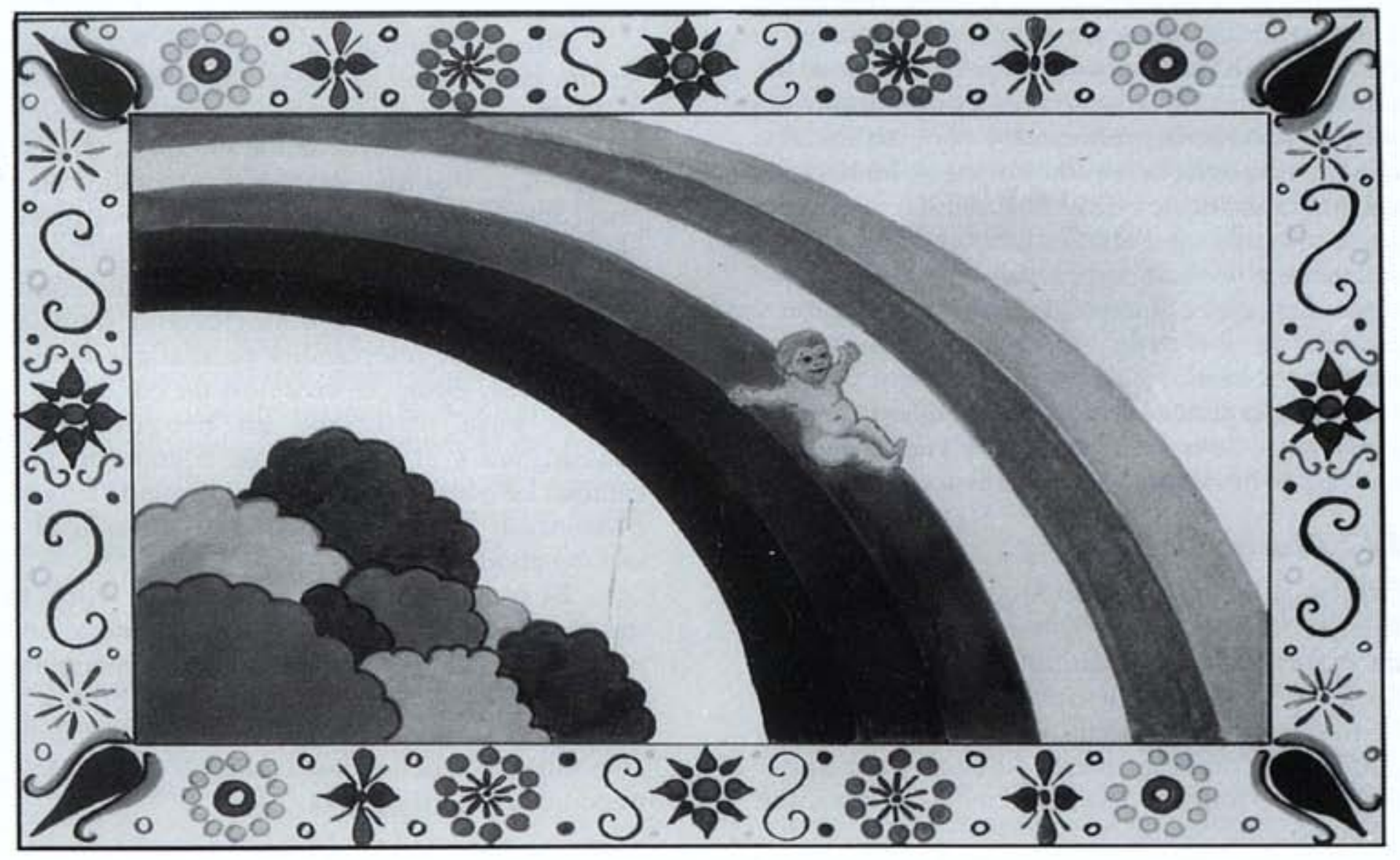


costo. Además, otro resultado positivo se observó en el aumento de la demanda de cursos de alfabetización, y en algunos casos la comunidad organizó otras actividades, como el "dia médico" donde se brindaban servicios de salud reproductiva.

\section{La Importancia de Involucrar a las Mujeres en el Desarrollo de Materiales de Salud}

Para la mayoría de las participantes, los cursos fueron un evento importante en sus vidas. Las mujeres se pusieron sus mejores ropas para asistir a las clases, incluso cuando tenían que caminar $14 \mathrm{~km}$ para llegar al curso. A pesar de ello, estaban muy motivadas y acudian diariamente, ya que trabajando en grupo podian compartir información con otras mujeres como ellas.

Las participantes inmediatamente se identificaron con los dibujos -"gente como nosotras"- decian. Reconocerse como "nosotras" fue muy importante para estimular el diálogo entre las mujeres y también en la aceptación de los libros para colorear. La experiencia de colorear hizo el proceso más personal: "pintando, podemos poner color a la vida".

Puesto que las mujeres tomaron los libros como propios, ellas no sólo los guardaban y pegaban en las paredes, sino también los consultaban una y otra vez -comentando los dibujos que habían coloreado y compartiéndolos con miembros de la familia y amigos. Inmiscuir a las mujeres locales desde el comienzo de este proceso ayudó a que ellas encontraran el contenido relevante y de fácil comprensión; y debido a que estos mensajes e ilustraciones se desarrollaron y evaluaron en cada región respetando las tradiciones locales y el conocimiento que poseían, la audiencia se identificó más fácilmente con las pinturas y tuvo una mayor apertura a nuevos conceptos incorporados en las historias.

\section{El Futuro}

A la fecha, los folletos se han distribuido a lo largo del Perú con la colaboración de la División de Participación Comunitaria del Ministerio de Salud y la División de Alfabetización del Ministerio de Educación. Después de la publicación de los primeros folletos, Perú-Mujer produjo 19 folletos más sobre temas como salud

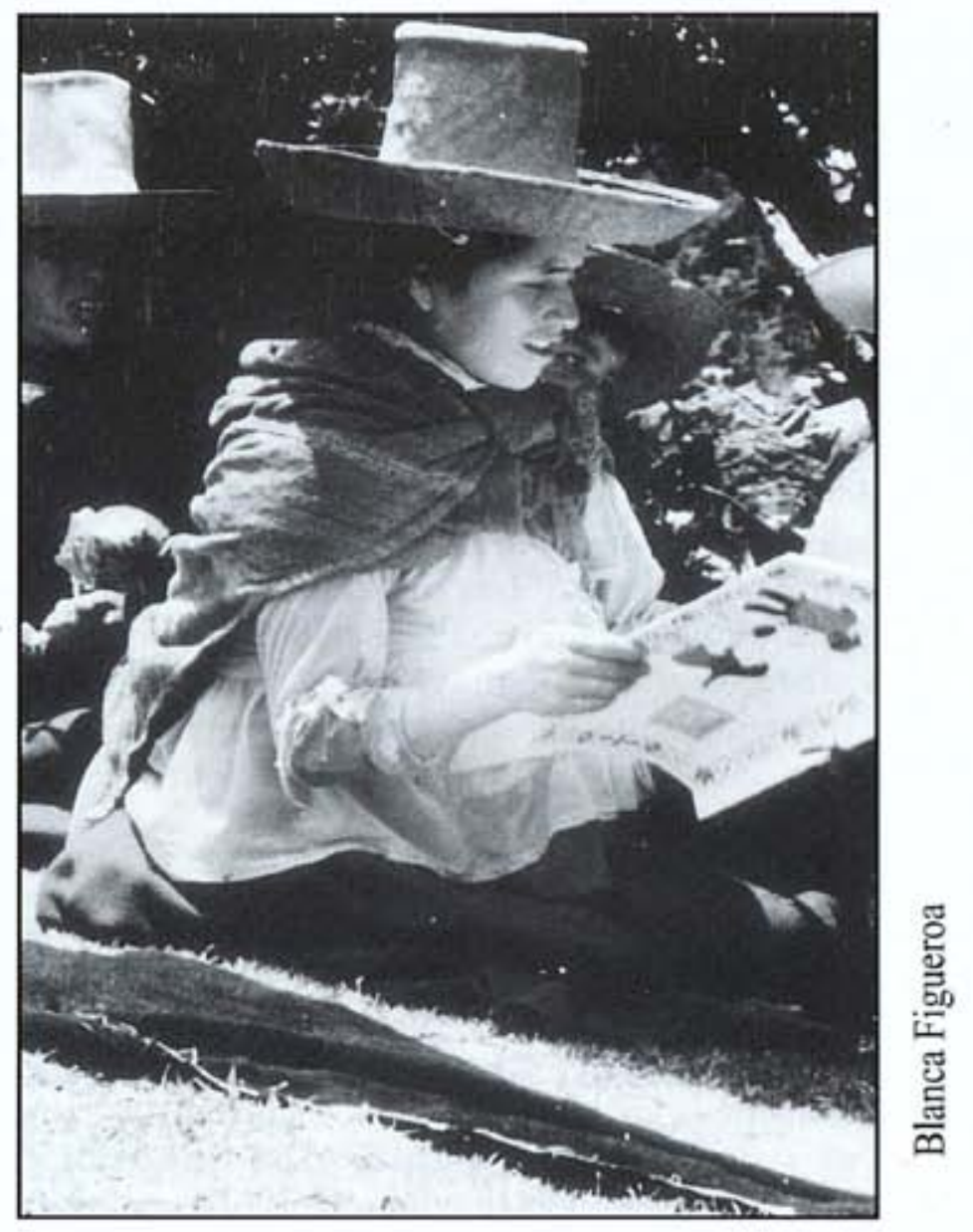

adolescente, mujeres y violencia, abuso sexual, organización comunitaria y salud.

Una reorganización interna en Perú-Mujer resultó en cambios en el personal y en el énfasis de la organización. Este tipo de trabajo ahora se ha transferido a la Asociación Grupo de Trabajo Redes. Aquellos que estaban involucrados en el proyecto de educación para la salud llevaron sus habilidades y experiencias sobre nuevos proyectos y constantemente están desarrollando materiales educativos de salud y planificación familiar. Además, están interesados en realizar nuevas actividades, como la creación de canciones y juegos para utilizarse en programas de adolescentes y el desarrollo de telenovelas para cambiar las actitudes hacia la planificación familiar e identificar las vías apropiadas para promover el uso del condón.

El trabajo de educación para la salud ha trascendido los limites institucionales. Esto se debe no sólo al impacto de la diseminación de materiales a poblaciones marginadas, sino también a la creación de un grupo de estudiantes y trabajadores comunitarios quienes han manejado y aplicado la metodologia participativa. 


\section{Temas Tabú: Videos de Salud Reproductiva por Mujeres de las Islas del Pacífico}

\section{Antecedentes}

Hasta mediados de los ochentas se sabía poco sobre las prioridades de salud de las mujeres en el Pacífico del Sur y se habian financiado pocos proyectos de mujeres. El material sobre salud reproductiva era escaso, no estaba diseñado especificamente para la región y las mujeres tenian poca injerencia en su desarrollo. En 1984-1985 dos australianas hicieron un estudio sobre salud reproductiva en el Pacifico del Sur para la Federación Australiana de Planificación Familiar. Las investigadoras se conectaron con la extensa red de grupos de mujeres que existe en las aldeas y pueblos de la región, escuchando y grabando lo que las mujeres del Pacífico Sur tenian que decir sobre sus necesidades y deseos respecto a su salud reproductiva.

Ellas tenian mucho que decir, pero la mayoría mencionó la necesidad de tener acceso a la información sobre anticoncepción, embarazo y enfermedades de transmisión sexual (ETS). Comentaron el problema que significaba hablar de estos temas en las familias y las comunidades, particularmente con los hombres. También plantearon el problema de los hombres que no toman responsabilidad en la anticoncepción o en el control de la propagación de las ETS.

Cuando se les preguntó qué medio les parecia el más apropiado para presentar la información sobre estos temas, las mujeres votaron por el video, ya que podía presentar la información en forma de relatos, siguiendo la tradición del Pacifico, y podrian presentarse de manera aceptable los temas que fueran propensos a tabúes culturales, particularmente sexuales, que frecuentemente limitan la efectividad del trabajo de la educación para la salud. A pesar de que la distribución de los equipos de video en la región es desigual, generalmente resultan accesibles y disponibles.

En 1978, la Federación Australiana de Planificación Familiar obtuvo financiamiento de la Oficina Australiana para la Asistencia al Desarrollo Internacional para producir videos en salud reproductiva que cubrieran las necesidades identificadas.

\section{El Proyecto}

Antes de comenzar el proyecto, se actualizó la investigación realizada anteriormente para verificar que las mujeres del Pacifico todavía tuvieran las mismas prioridades que habian expresado dos o tres años atrás. Esto trajo una nueva preocupación: el SIDA. Fue entonces, cuando se decidió producir tres videos de los siguientes temas: a) SIDA y el Pacifico del Sur; 2) Mejor segura, sobre enfermedades de transmisión sexual, y 3) Temas Tabú, una discusión sobre las actitudes de las mujeres hacia la menstruación, educación sexual y planificación familiar.

Los tres videos difieren, no sólo en el tema que tratan, sino también en el estilo de presentación. Las formas de presentación de cada uno de los tres temas fue seleccionada en numerosos talleres de planeación con mujeres del Pacifico.

SIDA y el Pacifico Sur utiliza dos figuras respetadas, una mujer académica y un médico, que presentan material controvertido con una voz de autoridad. La información explícita sobre SIDA se considera demasiado delicada para presentarla de otra forma que no sea a modo de "sermón", ya que eso le da cierta credibilidad a los mensajes y que ayuda a disminuir la resistencia general de discutir públicamente asuntos sexuales.

Mejor Segura es un drama sobre las enfermedades de transmisión sexual, el uso del condón y la responsabilidad sexual masculina. El video utiliza actores para crear la historia de un joven que se mueve entre la ciudad y los pueblos de sus novias. El video trata de exponer algunas diferencias en las actitudes de hombres y mujeres, y en áreas rurales y urbanas, además de promover discusiones acerca de las opciones para la prevención de ETSs.

Temas Tabú presenta a una extensa variedad de mujeres del Pacifico - viejas/jóvenes, urbanas/ rurales, con y sin estudios- hablando de sus experiencias, esperanzas y preocupaciones. La cinta incorpora escenas de la vida del pueblo, asi como la música de canciones tradicionales. El objetivo es propiciar discusiones sobre cuestiones de salud reproductiva y reconocer las experiencias comunes de las mujeres de la región. 


\section{Producción de videos}

Se eligieron las Islas Fidji del Pacífico como locación para filmar los videos por la diversidad de gente del Pacífico que refleja, asi como por la existencia de múltiples facilidades de producción a medios de comunicación. Además, el presupuesto no contemplaba la filmación en más de un país.

El proyecto fue administrado y realizado integramente por mujeres. A pesar de que los videos y su utilización eran el producto final del proyecto, el proceso de producción fue igual de importante. Las mujeres del Pacífico se incluyeron en todas las fases, desde la investigación inicial hasta la producción y distribución. El plan original era usar un equipo de filmación de mujeres del Pacífico, pero no se encontró ninguno y se trajo uno desde Australia, con el acuerdo de que una parte del proyecto consistiria en capacitar un grupo de mujeres para filmar. La selección de los entrenadores fílmicos se basó en la participación que habian tenido anteriormente en medios, interés, antecedentes en actividades de mujeres y potencial para futuros proyectos.

Los guiones se desarrollaron con la intención de utilizarse sólo como guías que podrían modificarse durante los talleres con las mujeres del Pacífico. Los talleres continuaron hasta que se determinó un lenguaje, creencias, valores, estilo de presentación, duración, participación religiosa y prioridades. Por ejemplo, debido al importante papel que juega la religión en la vida de las personas del Pacífico, las mujeres quisieron que las dos iglesias principales se representaran en el video de SIDA, para dar credibilidad y autoridad a los mensajes; además, debido a que los hombres del Pacífico no tienden a involucrarse en "asuntos de mujeres", ellas quisieron que su video de ETS se enfocara en la necesidad de que los hombres participen activamente.

El proyecto se diseñó tomando en cuenta la sensibilidad cultural y religiosa de la gente que estaba involucrada. A pesar de que inicialmente las mujeres se resistian a hablar delante de la cámara, su deseo de hacerlo era aún mayor; el apoyo por parte del equipo de filmación las ayudó a superar su reserva. En una ocasión, la filmación provocó recuerdos dolorosos acerca del pasado de una mujer y ella comenzó a llorar. En lugar de utilizar la situación, el equipo de filmación se detuvo y empezó a compartir sus propias experiencias reproductivas. Esto mostró que las experiencias de las mujeres trascienden nacionalidades y que la filmación podría resaltar

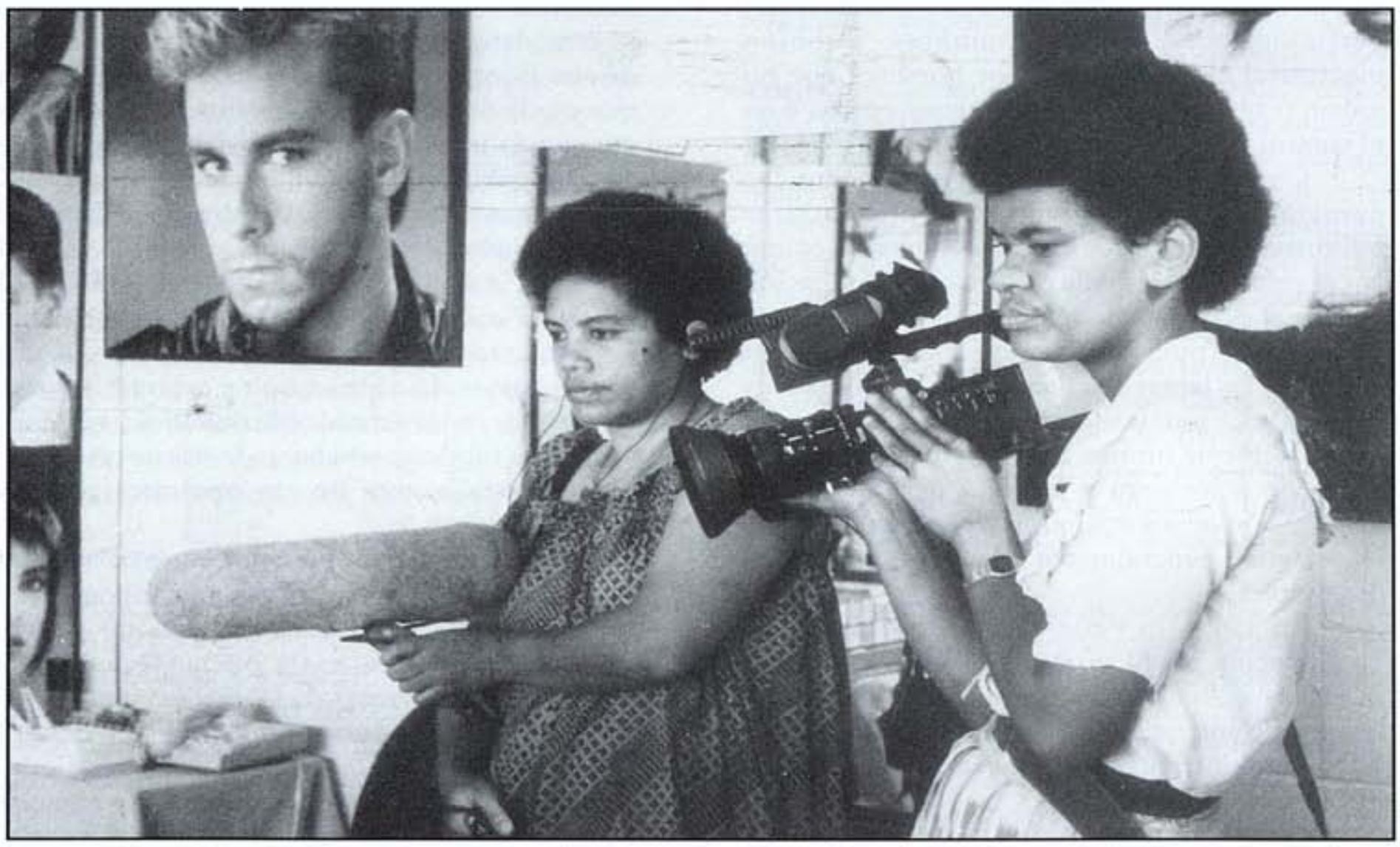


la experiencia universal en un sentido positivo, más que hablar de la experiencia en sí de las mujeres del Pacífico.

La región del Pacífico Sur es muy diversa tanto racial como culturalmente. A pesar de que los tabúes sexuales se toman muy seriamente, varian de país a país, por lo que era difícil decidir cuándo una escena, como en la que un condón es colocado en un modelo del pene erecto, sería aceptada por la audiencia de la región. Después de numerosas discusiones con grupos de mujeres, se decidió que la escena debía ser incluida y no hubo ninguna retroalimentación negativa. Esto subraya la importancia de incorporar comentarios de la audiencia sobre estilo y contenido a lo largo de todo el proceso de desarrollo del material.

\section{Distribución y Uso}

El lanzamiento de los videos fue previsto para que coincidiera con la cuarta conferencia regional de mujeres llevada a cabo en Fidji, en septiembre de 1988. Grupos de mujeres del Pacífico asistieron a las conferencias. También se anexaron imágenes de las diversas localidades donde se llevaron a cabo las filmaciones, incluyendo los pueblos. Se invitó a representantes de medios a estas tomas, dando como resultado artículos en periódicos y entrevistas en Radio Fidji. Se enviaron anuncios para que la gente de la región se pudiera poner en contacto. La retroalimentación de estos primeros contactos fue favorable.

Actualmente los videos se están distribuyendo entre asociaciones de planificación familiar independientes y no gubernamentales en Papúa-Nueva Guinea, las Islas Salomón, Tonga, Fidji y Samoa Occidental; y los están utilizando en 16 países del Pacífico. Ahora están siendo revisados por departamentos de salud y educación, grupos de mujeres y jóvenes, organizaciones no gubernamentales involucradas en la educación para la salud e iglesias. Los videos de SIDA y el Pacifico Sur y Mejor Seguro se han proyectado en la televisión nacional de Papúa-Nueva Guinea y Palau, y son ahora "videos recomendados" como currícula para la educación superior. Se persiguió un asunto particularmente innovador en la distribución en Fidji, donde el principal distribuidor comercial de videos para rentar incluyó la película sobre el SIDA a modo de "corto" en películas populares que rentaban. El gobierno australiano también compró copias para distribuir entre los trabajadores de salud en áreas de Australia con grandes comunidades de las Islas del Pacífico.

En 1989 se llevó a cabo una evaluación del proyecto, tanto del proceso de producción del video, como del impacto de los videos en términos de distribución, aceptabilidad, adecuación y efectividad. Se reconoció la habilidad de los videos para fomentar discusiones sobre temas que son evitados públicamente. Tanto los educadores como la audiencia hicieron hincapié en dos áreas en las que los videos eran excelentes: su sabor del Pacífico y la habilidad para fomentar discusiones.

A pesar de que el proyecto se diseñó como un recurso educativo para las mujeres, los hombres también mostraron un enorme interés en cuestiones de salud reproductiva. Los estrenos de los videos proyectados provocaron numerosas solicitudes, tanto de hombres como de mujeres, para la realización de videos sobre sexualidad y métodos anticonceptivos enfocados a los hombres. Cuando se produjo Temas Tabú, las mujeres se resistían a que los hombres de las Islas del Pacífico vieran la filmación, ya que esperaban una respuesta negativa por parte de ellos, acerca de que las mujeres expresaran sus pensamientos y sentimientos de esta forma. Como consecuencia, las primeras emisiones del video se proyectaron sólo a mujeres y a hombres que no eran de las Islas del Pacífico. Sin embargo, una vez que empezó la distribución, no fue posible controlar el tipo de audiencia que veía el video, con lo que la evaluación fue particularmente interesante para aprender de las reacciones de los hombres del Pacifico a la filmación. Se encontraron reacciones muy positivas, los hombres estaban fascinados por la habilidad de las mujeres para hablar de estos temas y querian una oportunidad para hacer lo mismo, especialmente en temas como anticoncepción y el rol sexual del hombre. Hubo muchas solicitudes para realizar Temas Tabú en versión masculina.

La distribución del video continúa siendo un problema en la región: aunque se esta utilizando ampliamente, su disponibilidad es muy dispar, se utiliza más en áreas urbanas y sus alrededores. Para el futuro, se buscará una distribución más amplia a través de la promoción interpersonal en la región y aumentando el número de distribuidores en organizaciones regionales. Además, su uso podria ser reforzado si se acompaña de material impreso que ofrezca detalles específicos sobre la audiencia a la que está dirigida, metas y objetivos de cada cinta, y sugerencias para su uso. 


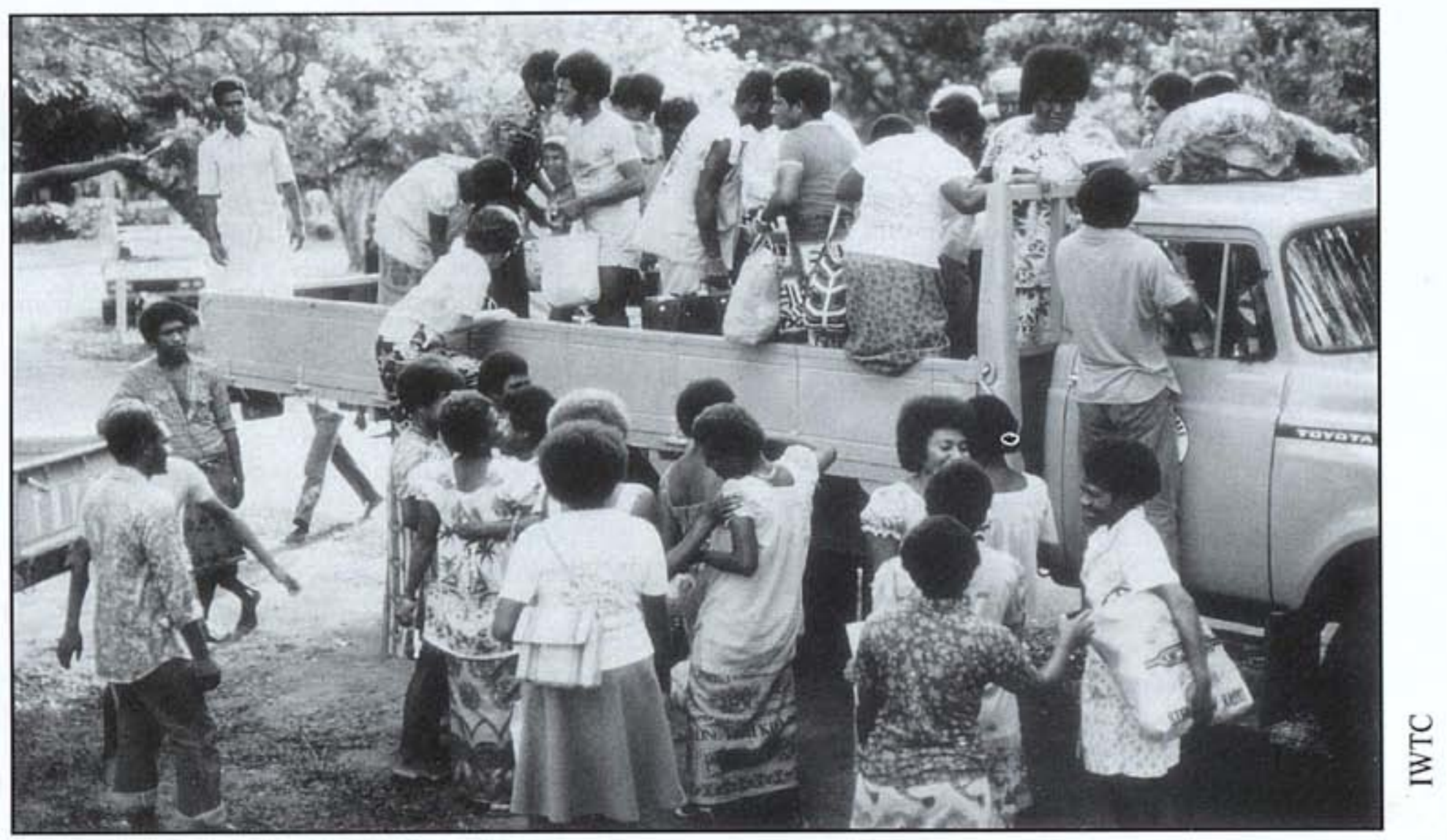

El lenguaje es otro problema. El inglés es el único lenguaje común en el Pacífico, por lo que si sólo se produjera una versión para la región, ésta debería estar en inglés. Sin embargo, las versiones en lengua local serían más efectivas para alcanzar a la gente de áreas rurales y gente mayor. Afortunadamente, se está fundando un proyecto de seguimiento, el cual traducirá el video a cinco lenguas del Pacifico. El trabajo de traducción también será realizado por grupos de mujeres de la comunidad.

Se podria haber reforzado el reconocimiento del equipo filmico con un certificado al término de su aprendizaje, para evidenciar sus esfuerzos. Sin embargo, a pesar de la falta del reconocimiento formal, los miembros del grupo de filmación han utilizado la experiencia tanto para obtener mejores trabajos como para ascender en su trabajo actual. Ahora, todos se sienten seguros de que podrán producir sus propios videos en el futuro.

El hecho de que los gobiernos a lo largo del Pacífico están utilizando ahora un recurso no gubernamental producido completamente por mujeres, es un reconocimiento a las habilidades de las mujeres involucradas. 


\section{Discusión}

Las diferencias entre los tres proyectos descritos muestran que no hay un patrón estándar para desarrollar mensajes y hacer llegar exitosamente información sobre salud a las mujeres. Sin embargo, los estudios de caso pueden estimularnos para pensar algunos principios básicos que pueden ser de ayuda para los involucrados en esfuerzos similares. Las lectoras que quieran aprender más sobre proyectos individuales, pueden recurrir al Apéndice, donde aparece una lista con direcciones para mayor información y otros recursos.

\section{Sin Atajos}

El desarrollo de materiales de información de alta calidad toma tiempo. Cada capítulo del libro del Colectivo para la Salud de las Mujeres de El Cairo se revisó cuatro veces, incluso antes de la evaluación inicial; tanto el contenido como la estrategia se discutieron ampliamente hasta que se alcanzó el consenso. En el Perú, se puso especial atención en los detalles, como en los vestidos que aparecen en las ilustraciones, lo que significa que hubo numerosas versiones para aumentar la efectividad del mensaje. La consulta entre mujeres del Pacífico, que son culturalmente heterogéneas, fue necesaria para lograr la aceptabilidad de los temas potencialmente sensibles. La producción podría haber sido más rápida sin eso, pero a juzgar por la evaluación, los videos no hubieran tenido el mismo impacto.

\section{Conoce Ia Audiencia}

Uno de los aspectos de los tres proyectos que más tiempo consumió fue la interacción con la audiencia a la que iba dirigido el producto. Esto se logró de diferentes formas -seminarios, reuniones con grupos de mujeres, discusiones en grupos focales-y en diferentes etapas del proceso, pero en cada caso estas vías suministraron información indispensable para el producto final. Este proceso no siempre se aplica en el desarrollo de materiales de información de la salud, en los que las mujeres son la audiencia. Esto fue crucial, ya que raramente se les pregunta sobre sus necesidades y opiniones.

Suponer lo que las mujeres quieren o pueden hacer puede ser engañoso. Los productores del video Temas Tabú podrían haber aceptado la creencia convencional de que las mujeres del
Pacifico no discuten temas sexuales y simplemente producir un video didáctico; sin embargo, invirtieron tiempo hablando con grupos de mujeres a lo largo de la región. Esto les dio una imagen completamente distinta de la situación. El resultado es una producción sensible y dinámica que permite a otras mujeres del Pacífico, aprender de las discusiones de sus "hermanas" sobre sus experiencias y sentimientos en salud reproductiva.

\section{... y Su Variedad}

A pesar de que las necesidades de salud y los problemas tienen mucho en común, es un error el tratar a las mujeres como una audiencia homogénea. En el Perú, el proyecto tuvo que adaptar los materiales de información de planificación familiar para cada una de las tres principales regiones culturales del pais, y el libro de salud de El Cairo tuvo que ser sensible a las creencias religiosas, tanto cristianas como musulmanas; la elección del inglés como idioma de los videos del Pacífico ha permitido que sean usados a lo largo de la región, pero en algunos casos a limitado la audiencia, con el resultado de que las mujeres mayores y aquellas de áreas rurales no están incluidas.

\section{¿Dibujos, Libros,Películas?}

La elección de qué medio utilizar es dificil y, una vez más, las decisiones deben basarse en el conocimiento de la audiencia. Los materiales pictóricos usados en los cursos para analfabetas seguirán siendo importantes para llegar a las mujeres mayores aún en aquellos países donde la educación formal se vuelve cada dia mas accesible para los jóvenes. Sin embargo, la demanda de material escrito necesita ser revisada continuamente ya que el perfil educativo de las mujeres está cambiando y se necesitan considerar otros medios populares emergentes, tales como las revistas para mujeres. Los videos también pueden ser apropiados en lugares donde la audiencia tiene acceso a tecnología y donde el mantenimiento no es un problema. Como la autora del reporte del Pacífico comenta, el impacto de los videos probablemente podria haber sido mayor si se hubiera acompañado de material escrito explicando los objetivos y su uso, y si hubieran sido distribuidos a lo largo de una gira promocional o de comunicación interpersonal. 


\section{Algunas Lecciones Técnicas}

Muchos problemas técnicos que pueden surgir en la producción de los materiales de información sobre salud -como la comprensión de mensajes visuales- pueden aplicarse igualmente a audiencias masculinas y femeninas. Pero como las mujeres están menos familiarizadas con el "mundo exterior", algunas veces es necesario hacer un esfuerzo para asegurar que el material no sólo les llegue, sino que sea entendido por la población femenina. Los estudios frecuentemente se quejan acerca de que los materiales son discutidos por un grupo indefinido de habitantes de "pueblos" o "comunidades", pero a menos que se hagan intentos especiales solicitando las contribuciones de la mujer, se seguirá consultando en las comunidades preferentemente a hombres y se estarán obteniendo sus puntos de vista, lo cual no garantiza que se representen los de las mujeres.

Cuando las mujeres son la audiencia buscada, su participación es esencial, no sólo para asegurar que los mensajes sean adecuados, sino también para asegurar que son relevantes ante los problemas que perciben las mujeres y para su visión del mundo. En el Perú, "traducir" los consejos de las mujeres a dibujos e historias significó que fueran algo más que simplemente reconocibles, las mujeres se identificaban con ellos.

\section{Importancia del Proceso}

El hecho de que las mujeres raramente tengan voz en la toma de decisiones, hace que el desarrollo total del proceso descrito en estos estudios de caso rompa con los moldes. Su valor se extiende tanto a las mujeres a las que va dirigido como a las que están involucradas en la producción. Participar en cursos y obtener un diploma, ser miembros de un grupo focal de discusión, responder al material de la evaluación inicial, hablar sobre experiencias personales en una filmación -todo esto puede reforzar las redes de mujeres y elevar la autoestima. Para los productores del material, se sirven las mismas funciones al implementar las actividades de los proyectos: formar un colectivo de mujeres, capacitar en metodología participativa, tomar parte en discusiones e interactuar con proveedores de servicios. En el Pacífico, se capacitó a un equipo de filmación compuesto exclusivamente por mujeres, abriendo nuevas oportunidades de empleo para ellas después del proyecto. Sin importar que la recompensa sea material, profesional, social y personal, aquellas inmiscuidas en la implementación del proyecto sintieron que habían ganado mucho más la simple producción del material informativo.

\section{Construyendo sobre la Inversión}

Todos los proyectos discutidos aquí están orientados a expandir o crear nuevas actividades que hagan uso de las experiencias y resultados obtenidos, ampliando así el impacto del material que ha mostrado ser efectivo. Igualmente, la experiencia obtenida por los participantes puede ser utilizada en futuras actividades para influenciar grupos de personas.

En El Cairo, donde se invirtió mucho tiempo y esfuerzo para la preparación del material del libro, se incluyeron sugerencias para el futuro, como convertir capitulos individuales en folletos y ampliar la difusión de los mensajes a través de otros medios como en revistas para mujeres; en el Perú, las mujeres están considerando otras formas de enviar mensajes educativos a través de canciones, juegos y telenovelas; en el Pacífico del Sur, la respuesta positiva de los hombres a los videos para mujeres puede conducir a un proyecto que grabe las perspectivas de salud reproductiva de los hombres. También se están traduciendo los videos existentes en cinco lenguas del Pacífico.

\section{Vínculos entre Información y Servicios}

Involucrar a los proveedores de servicios en el proceso de desarrollo y diseminación de información sobre salud reproductiva para mujeres puede dar muchos dividendos. Los lazos con los trabajadores de la salud pueden asegurar que la información provista describa adecuadamente los servicios disponibles, de tal forma que las expectativas de la mujer sean reales. Mientras asesoraban técnicamente durante la producción del libro de El Cairo, los miembros del colectivo que tenian capacitación médica tuvieron oportunidad de engancharse en un debate que sobrepasaba sus perspectivas sobre la salud de la mujer. Los materiales de Perú-Mujer fueron producidos para ser usados por promotores y trabajadores de la salud en comunidades, los cuales han ayudado a pre-probar los materiales con mujeres en comunidades locales. En el video de SIDA y el Pacífico Sur, la participación de médicos ayudó a 
dar credibilidad a la presentación de un material sensible y a vincular el material con asociaciones de planificación familiar del Pacífico, lo que fue valioso tanto durante la producción como durante la distribución de los videos a lo largo de sus redes.

El material de educación para la salud desarrollado por y para mujeres permite a las mujeres mismas tomar conciencia de los servicios disponibles, tener más confianza en su uso y estar más dispuestas para movilizarse en la demanda de la mejora de los servicios. En Perú, los cursos de información sobre salud llevaron a una demanda de textos de enseñanza y a la organización de actividades como el "día médico", donde se suministraban servicios de salud reproductiva.

Más que esto, el vinculo entre información y servicios es fundamental en un sentido conceptual. La tendencia de poner mas énfasis en una atención de calidad y el incorporar la perspectiva del usuario en los servicios se extiende lógicamente al involucrar a la mujer en el desarrollo de materiales de información. Los materiales basados en el respeto a la cliente -sus necesidades, creencias y contribuciones- serán aquellas que las mujeres entiendan y usen.

\section{Résume en français}

L'information est la clé pour comprendre et faire face au changement. C'est la condition pour une meilleure prise de conscience de soi-même et pour donner aux individus les moyens d'exercer plus de contrôle sur leur propre vie. Probablement nulle part ailleurs n'est la question de l'accès à l'information aussi cruciale que dans le domaine de la santé des femmes - particulièrement en ce qui concerne la santé de la reproduction des femmes. Dans la seconde moitié de ce siècle, les professionnels de la médecine ont eu tendance non seulement à se sentir propriétaire du savoir en matière de santé de la reproduction 'mais encore à refuser de le partager avec les dispensateurs traditionnels de soins, c'est-à-dire, les sagesfemmes et les femmes elles-mêmes.

En conséquence, les groupements féminins oeuvrant pour la santé des femmes sont devenus particulièrement actifs et ont commencé à se faire entendre au cours de ces dernières années. Gräce, surtout, aux efforts déployés par les femmes travaillant à la base ou en milieu académique ou hospitalier, les professionnels de la planification familiale ont fini par réaliser que pour favoriser l'adoption et l'utilisation continue d'une méthode contraceptive, on ne pouvait se contenter de motiver les clients potentiels; il fallait, en fait, leur donner des informations complètes et pertinentes sur les méthodes contraceptives et s'assurer, par ailleurs, que les clients pouvaient se les procurer facilement. On s'est également rendu compte que, pour être utile, l'information devait être intelligible et attrayante pour le public visé et être présentée sous une forme qui reflète la réalité.

\section{Matériele d'information par et pour les femmes: Quelques défis à relever}

Le développement de matériels d'information sur la santé par et pour les femmes se heurte non seulement à des problèmes techniques courants mais également à des obstacles plus fondamentals. Les femmes, plus particulièrement les femmes pauvres, risquent souvent d'être marginalisées par la société. Elles sont également plus nombreuses que les hommes à être analphabètes ou à avoir perdu la capacité de lire par manque de pratique. En outre, on les intimident ou les empëchent d'avoir accès a l'information moderne et elles sont tenues à l'écart de toutes les prises de décisions.

Le processus de développement de matériels sur la santé par et pour les femmes peut constituer un contexte sécurisant dans le cadre duquel les femmes ont la possibilité de poser des questions, de parler de leur vécu et d'échanger des informations sur des sujets qu'ils seraient impossible d'aborder dans un environnement mixte. Un tel processus aide également les femmes à se valoriser puisqu'elles s'apperçoivent qu'elles ne sont pas seules, que d'autres femmes partagent les mêmes problèmes et préoccupations et qu'elles peuvent apprendre de leurs expériences mutuelles. 


\section{Les études de cas}

Préoccupées par le manque de connaissances des femmes dans leur région sur leurs besoins en matière de santé, 25 femmes du Caire, de milieu social, de groupes d'âge et de catégories professionnelles très différents, ont décidé de former "Collectif du Caire pour l'information des femmes sur la santé". S'inspirant de "Notre corps, nous-mêmes" le fameux livre publié par le "Collectif de Boston pour l'information des femmes sur la santé", leur intention était de publier un ouvrage sur la santé qui serait écrit exclusivement par des femmes et du point de vue des femmes égyptiennes.

Le fruit de leurs efforts s'intitule "Vie et santé des femmes en Egypte". Il s'agit d'un guide sur la santé destiné aux femmes de la région et reflète des questions culturelles et des circonstances contemporaines particulieres à l'Egypte. Publié en 1991, ce guide fut développé à travers un long processus de négociations et de compromis. Il ne s'agit ni d'une traduction ni d'une adaptation mais d'un ouvrage inédit et est entièrement rédigé du point de vue des femmes dans un style amical et à la portée de tous. C'est également un livre objectif puisqu'il n'essaye d'imposer aucune vue particulière à ses lectrices mais au contraire de les amener à tirer leurs propres conclusions. Le livre se vend même mieux que prévu et une deuxième impression aura lieu début 1992.

Peru-Mujer, ONG péruvienne, en collaboration avec PATH (Programme de Technologie Appropriée en Santé) a entrepris un projet pour développer des brochures illustrées sur la planification familiale et la vaccination à l'intention des femmes illettrées et peu instruites. Les concepteurs ont adopté une approche centrée sur les femmes en faisant une utilisation positive des connaissances existants chez les femmes et de leur vécu et ont crée un climat de confiance propice à combattre les idées fausses et à faire cesser les pratiques néfastes.

Des brochures différentes ont été développées pour chacune des trois régions du Pérou et, dans chacun des cas, les concepteurs ont pris soin de les tester avec les femmes. Les brochures ont ensuite été utilisées dans des cours de formation. L'un des aspects uniques de ce projet était que les femmes (et souvent leurs enfants et même leurs maris!) coloriaient eux-mêmes les illustrations avec des crayons de couleurs qu'on leur avait donnés. Pour bien des femmes, c'était la première fois qu'elles tenaient un crayon de couleur entre leurs doigts; cette activité non seulement développait l'intérêt des femmes mais rendaient les brochures plus valables non seulement à leurs propres yeux mais aux yeux de la collectivité toute entière.

Une évaluation du projet a révélé que l'information avait bien été mémorisée et que le taux de fréquentation des services de santé et de planification familiale avait augmenté. Parmi les autres résultats positifs, il convient de noter les nombreuses demandes de participation à des cours pour apprendre à lire et à écrire et, dans certains cas, d'organisation d'activités au niveau de la collectivité

Dans le Pacifique Sud, l'on a demandé aux femmes quels étaient leurs besoins en matière de santé de la reproduction et quels types de matériels pouvaient, selon elles, le mieux communiquer les renseignements qu'elles souhaitaient recevoir. Le résultat fut un projet vidéo entièrement réalisé par des femmes et du point de vue des femmes avec la production des trois vidéos suivantes: 1) Le Sida et le Pacifique Sud; 2) Mieux vaut être prudent, consacré aux maladies sexuellement transmissibles; et 3) Conversations tabous, une discussion sur l'attitude des femmes envers la menstruation, l'éducation à la vie familiale et la planification familiale.

Du début à la fin, le projet a été entièrement réalisé par des femmes. Bien que les vidéos et leur utilisation étaient le produit final, le processus de production était d'une importance toute aussi capitale. Les femmes de la région étaient inclues à toutes les phases du projet depuis la recherche initiale jusqu'a la production et la distribution. Etant donné qu'aucune équipe de tournage féminine n'était disponible sur place, l'on a fait venir une équipe australienne sous condition qu'elle formerait une équipe locale dans la production de vidéos.

A présent, les vidéos sont utilisées dans 16 pays du Pacifique Sud. Une évaluation réalisée en 1989 a révélé que les vidéos sont capables de susciter des discussions sur des sujets dont auparavant il ne fallait pas parler ouvertement. Selon les éducateurs et les spectateurs, les deux domaines dans lesquels les vidéos excellent sont le fait qu'elles rendent bien l'atmosphère du Pacifique et leur capacité à stimuler la discussion. 


\section{Apéndice}

La lista a continuación es para contactar organizaciones y/o personas involucradas en el desarrollo del material presentado en esta edición de Calidad/Quality/Qualité, además de otras organizaciones relacionadas con la producción y/o diseminación de materiales de salud desarrollados por y para mujeres. También aparecen listadas varias publicaciones de posible interés.

\section{Recursos}

Colectivo del Libro de Salud de Mujeres de El Cairo: (Cairo Women's Health Book Collective) c/o Delta Associates

12 Muamal el Sukkar

Garden City

El Cairo, Egipto

Para mayor información sobre el desarrollo de materiales para la salud de las mujeres en Perú:

Blanca Figueroa

Grupo de Trabajo Redes

Apartado Postal 1578

Lima, Perú

Para mayor información sobre el video del

Pacifico del Sur:

Family Planing Federation of Australia

39 Gelis Court

Deakin ACT, Australia

Autores del libro Our Bodies, Ourselves.

Trabajo con grupos en otros países para

producir materiales de salud.

Boston Women's Health Book Collective

P.O. Box 192

West Somerville, MA 02144, EU

Servicios de Información y comunicación para mujeres. Publicaciones, asistencia técnica y capacitación en habilidades de comunicación y dirección.

ISIS International

85-A East May St.

Philamlife Homes

Quezon City

The Philippines

$\mathrm{y}$

ISIS International

Casilla 2067

Correo Central

Santigo, Chile
Proyecto Nacional de Salud de Mujeres Negras (National Black Women's Health Project)

1237 Gordon St., SW.

Atlanta, GA 30310 EU

Fué originalmente un programa basado en los E.U., ahora tienen un programa internacional. Amplia experiencia trabajando con mujeres privadas de sus derechos y ayudándolas a tomar la responsabilidad para cuidados de su salud.

\section{Publicaciones}

(Por favor contactar directamente con los editores para conocer la disponibilidad, costos y cargos de envio, que puedan aplicarse).

Developing Health and Family Planing Print Materials for Low-Literature Audiences: A Guide, por Zimmerman, Newton, Frumin y WITTET Programa para Tecnologia Apropiada en Salud (PATH) (Wittet Program for Appropiate Technology in Health)

1990 "M" Street, N.W.

Washington, D.C. $20036 \mathrm{EU}$

Teléfono: (202) 822-0033

In Her Own Image: Films and Videos

Empowering Women for the Future

Media Network

39 W. 14th. Street

Suite 403

New York, NY 10011 U.S.A

Teléfono: (212) 929-2663

Asia and Pacific Women's Resource and Action Series: Health

Asia \& Pacific Development Centre

P.O. Box 12224

Kuala Lumpur 50770, Malasya

Teléfono: 603-254-8088 


\title{
Sobre las Autoras
}

Valerie Hull es demógrafa con amplia experiencia de trabajo en paises en vías de desarrollo. Actualmente es Directora de la Sección de Mujer, Salud y Población de la Oficina Australiana de Asistencia para el Desarrollo. Cuando comenzó a desarrollarse el libro de Salud de El Cairo, Barbara Ibrahim era la Oficial del Programa Urbano en la oficina del El Cairo de la Fundación Ford; actualmente es Representante del Population Council Para Asia Occidental y África del Norte. Nadia Farah es Directora del Centro de Estudios del Desarrollo de El Cairo y coordinadora del Colectivo del Libro de la Salud de las Mujeres de El Cairo. Blanca Figueroa fue una de las fundadoras de Perú-Mujer y continúa su trabajo en el desarrollo de materiales de salud para mujeres como directora del Grupo de Trabajo Redes en Lima, Perú. Margaret Winn se involucró en la planeación, implementación y evaluación del proyecto del video de las Mujeres del Pacífico Sur, es actualmente asesora en salud reproductiva en el Pacífico Sur y educadora sobre SIDA basada en Australia.

\section{Comité Asesor Calidad/Quality/Qualité}

Ian Askew

George Brown

Judith Bruce

Ethel Churchill

Adrienne Germain

Margaret Hempel

Ann Leonard

Margaret McEvoy

John Paxman
Debbie Rogow

Jill Sheffield

Lindsay Stewart

Kerstin Trone

Nahid Toubia

Gilberte Vansintejan

Cynthia Steele Verme

Beverly Winikoff

Margot Zimmerman

\author{
Diseño: Ann Leonard \\ Foto de la portada: Institute of Cultural Affairs, \\ Bayad al Arab, Egypt \\ Formación e \\ impresión: mas impresos
}

Agradecemos tus comentarios y tus ideas para proyectos, que pueden ser incluidos en futuras ediciones de Calidad/Quality/Qualité. Si quieres incluirte en nuestra lista de correos, por favor, escribe a: Ann Leonard, Quality/Calidad/Qualité, Population Council, One Dag Hammarskjold Plaza, New York, NY 10017, EU 


\section{Sobre las Autoras}

Valerie Hull es demógrafa con amplia experiencia de trabajo en paises en vias de desarrollo. Actualmente es Directora de la Sección de Mujer, Salud y Población de la Oficina Australiana de Asistencia para el Desarrollo. Cuando comenzó a desarrollarse el libro de Salud de El Cairo, Barbara Ibrahim era la Oficial del Programa Urbano en la oficina del El Cairo de la Fundación Ford; actualmente es Representante del Population Council Para Asia Occidental y África del Norte. Nadia Farah es Directora del Centro de Estudios del Desarrollo de El Cairo y coordinadora del Colectivo del Libro de la Salud de las Mujeres de El Cairo. Blanca Figueroa fue una de las fundadoras de Perú-Mujer y continúa su trabajo en el desarrollo de materiales de salud para mujeres como directora del Grupo de Trabajo Redes en Lima, Perú. Margaret Winn se involucró en la planeación, implementación y evaluación del proyecto del video de las Mujeres del Pacifico Sur, es actualmente asesora en salud reproductiva en el Pacifico Sur y educadora sobre SIDA basada en Australia.

\section{Comité Asesor Calidad/Quality/Qualité}

Ian Askew

George Brown

Judith Bruce

Ethel Churchill

Adrienne Germain

Margaret Hempel

Ann Leonard

Margaret McEvoy

John Paxman
Debbie Rogow

Jill Sheffield

Lindsay Stewart

Kerstin Trone

Nahid Toubia

Gilberte Vansintejan

Cynthia Steele Verme

Beverly Winikoff

Margot Zimmerman

$\begin{array}{ll}\begin{array}{l}\text { Diseño: } \\ \text { Foto de la portada: }\end{array} & \begin{array}{l}\text { Ann Leonard } \\ \text { Institute of Cultural Affairs, } \\ \text { Bayad al Arab, Egypt }\end{array} \\ \begin{array}{l}\text { Formación e } \\ \text { impresión: }\end{array} & \text { mas impresos }\end{array}$

Agradecemos tus comentarios y tus ideas para proyectos, que pueden ser incluídos en futuras ediciones de Calidad/Quality/Qualité. Si quieres incluirte en nuestra lista de correos, por favor, escribe a: Ann Leonard, Quality/Calidad/Qualité, Population Council, One Dag Hammarskjold Plaza, New York, NY 10017, EU 


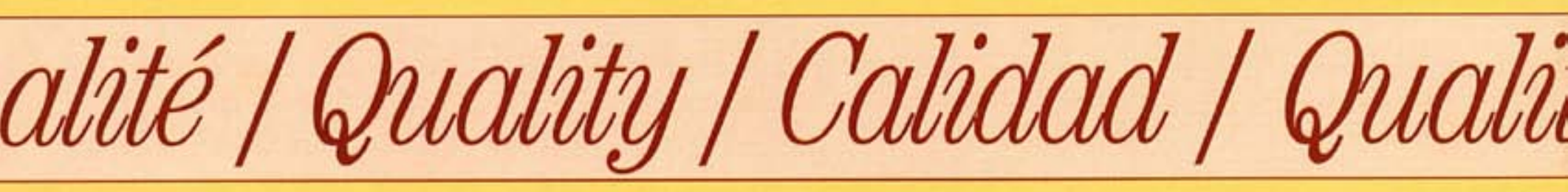

